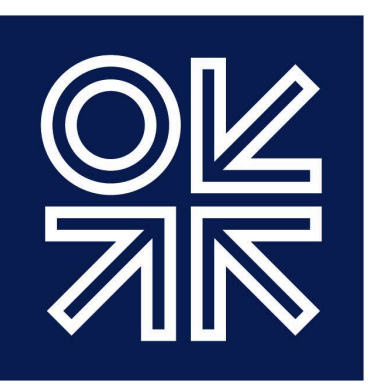

THE OXFORD

INSTITUTE

FOR ENERGY

STUDIES

October 2018

\title{
LNG Plant Cost Reduction 2014-18
}

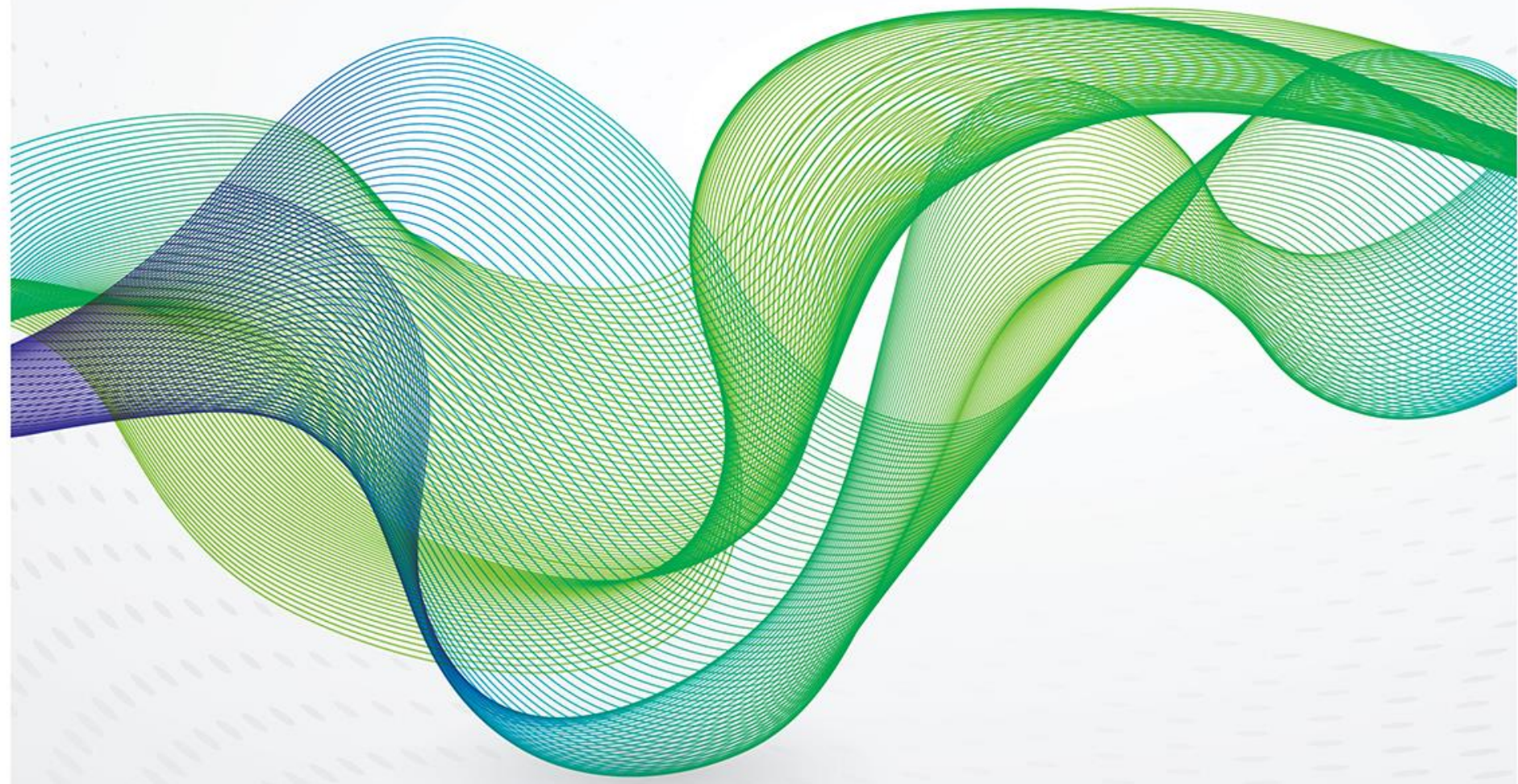



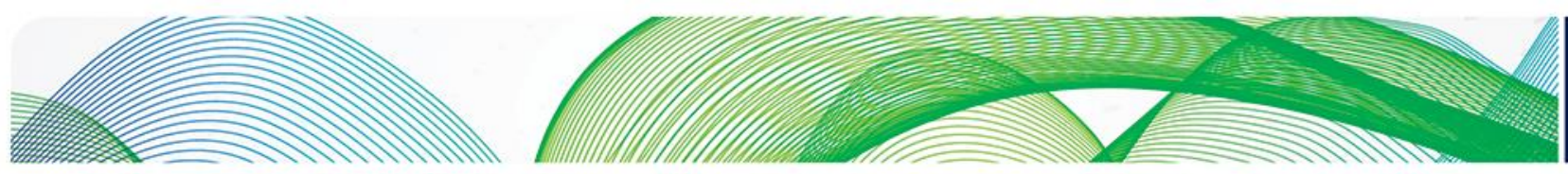

\section{잊조}

The contents of this paper are the author's sole responsibility. They do not necessarily represent the views of the Oxford Institute for Energy Studies or any of its members.

Copyright $\odot 2018$

Oxford Institute for Energy Studies

(Registered Charity, No. 286084)

This publication may be reproduced in part for educational or non-profit purposes without special permission from the copyright holder, provided acknowledgment of the source is made. No use of this publication may be made for resale or for any other commercial purpose whatsoever without prior permission in writing from the Oxford Institute for Energy Studies.

ISBN: 978-1-78467-120-4

DOI: https://doi.org/10.26889/9781784671204 

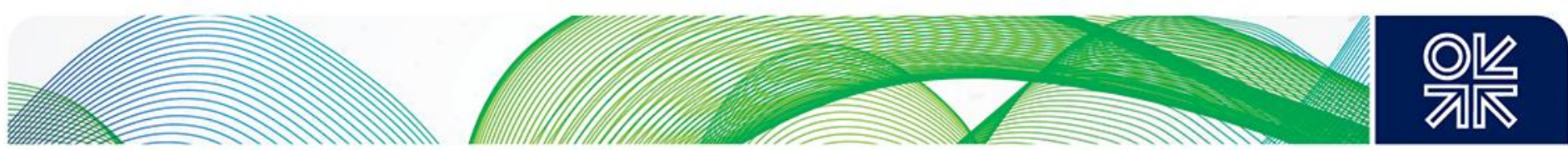

\section{Acknowledgements}

My thanks to fellow OIES colleague Claudio-Steuer for his contributions during the drafting of this paper.

My thanks also to the following industry colleagues for their review and comments on the draft:

Toby Chancellor-Weale, Chair, IChemE Oil and Natural Gas Special Interest Group (SONG)

Chris Spilsbury, LNG Specialists Ltd

John Rushbrook, Consultant 

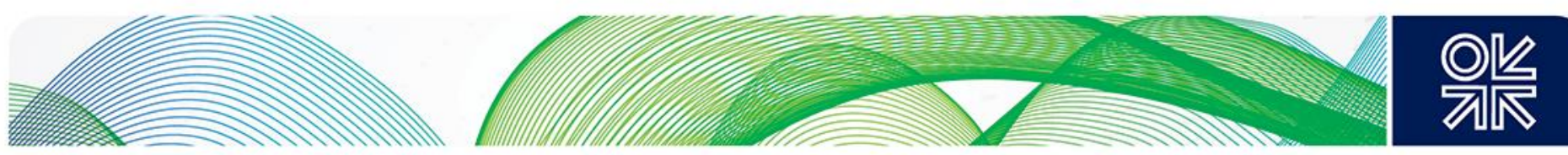

\section{Preface}

In his recent papers for OIES on the future of gas in Europe and the global energy economy, Jonathan Stern identified affordability as a key factor in determining whether gas would play a major role in Non-OECD countries. As the majority of traded gas will be LNG, the key question is therefore whether the cost of developing new liquefaction projects can be low enough to allow the gas to be competitive when it reaches the end consumer. This paper by Brian Songhurst aims to address this issue. His 2014 paper on the same topic identified the key causes behind the dramatic increase in costs seen in the period 2010-2014, and he now updates his analysis to look at the changes that have occurred in the period 2014-2018. The conclusions that he provides are vital to an understanding of whether project developers will be confident enough to proceed with new schemes that, according to Stern, must be able to deliver gas to market at a price less than $\$ 8 / \mathrm{mmbtu}$. While Songhurst suggests that there are certainly reasons for optimism, it is clearly a topic that merits continued research as the LNG industry moves into a critical phase of new FIDs for the 2020 s.

James Henderson

Director, Natural Gas Programme

Oxford Institute for Energy Studies 

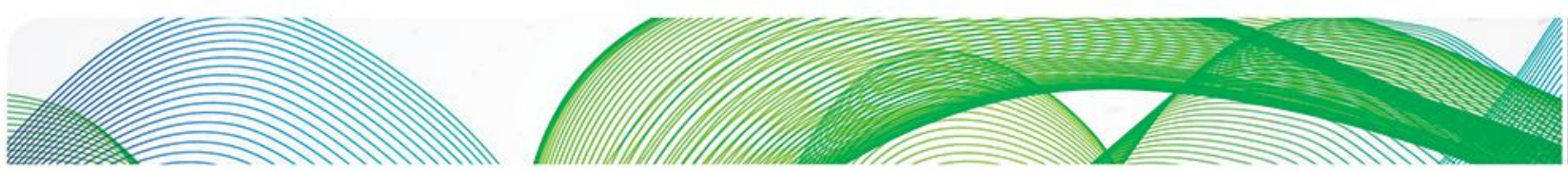
O贿

\section{Contents}

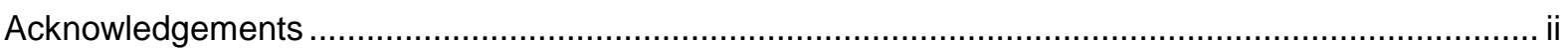

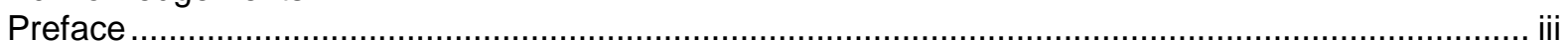

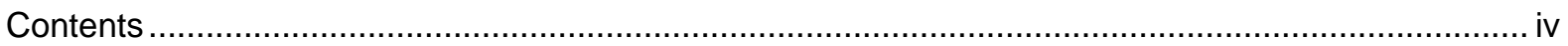

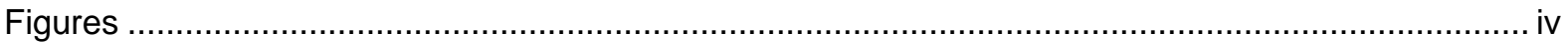

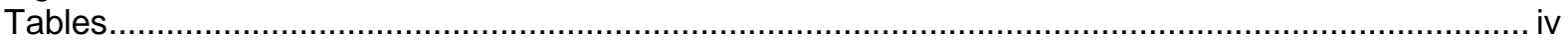

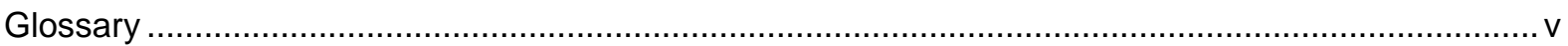

Chapter 1. Context and Reason for Paper.......................................................................... 1

Chapter 2. Review of Recent Cost Trends (2014-18) ........................................................... 4

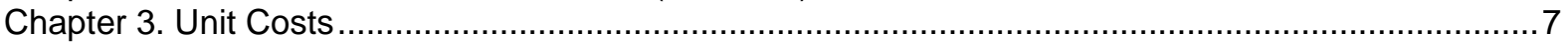

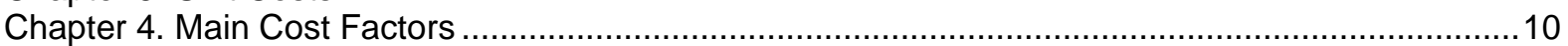

Chapter 5. Opportunities for Further Cost Reduction .............................................................13

Chapter 6. Operating Costs and Opportunities for Cost Reduction .................................................24

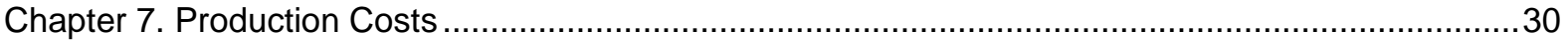

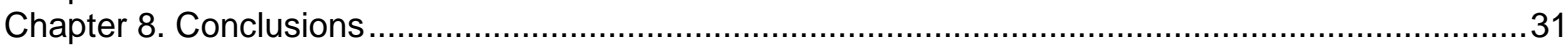

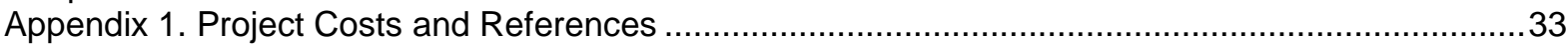

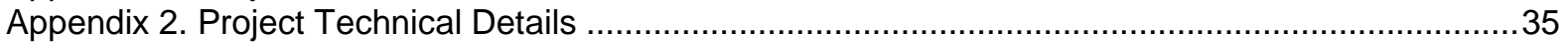

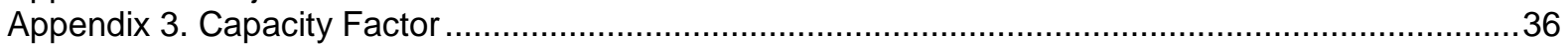

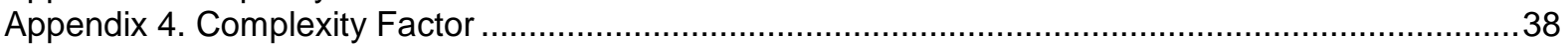

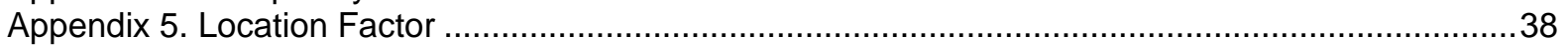

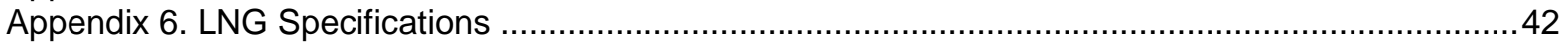

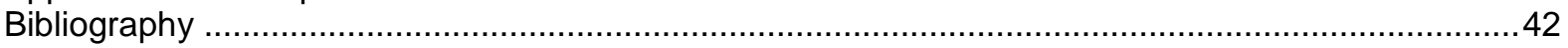

\section{Figures}

Figure 1: Overall Project Capital Costs $\$$ tpa Constructed 2014-18 ................................................ 1

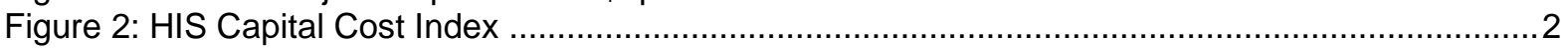

Figure 3: Liquefaction Plant Capital Costs $\$$ tpa Constructed 2014-18 .......................................... 4

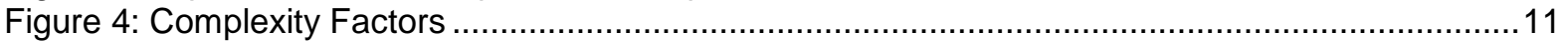

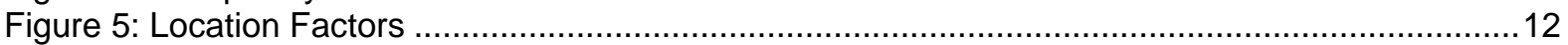

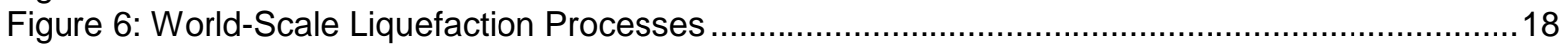

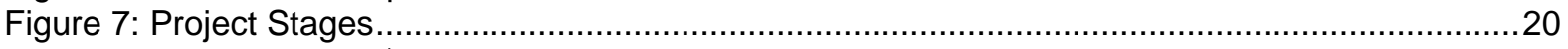

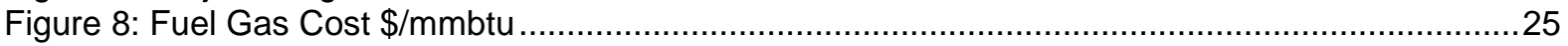

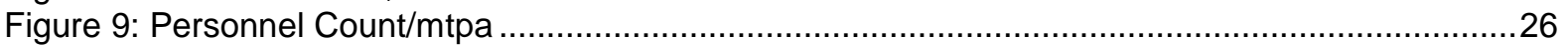

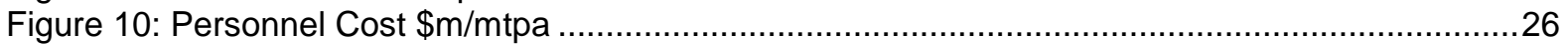

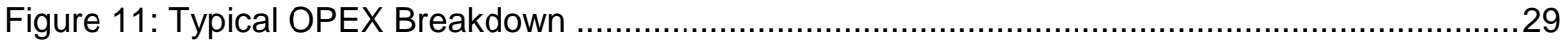

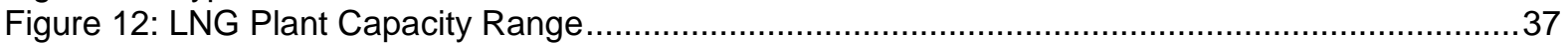

Figure 13: Complexity Factor (Lean Gas $=100 \%$ ) Based on Analysis of Projects Studied ..................38

Figure 14: Complexity Factors Based on KBR Paper but Adjusted \% Overall Project ........................38

Figure 15: Australian Dollar vs US Dollar Exchange Rates 2014-18 ............................................40

Figure 16: Location Factor (USA = 100\%) Based on Analysis of Projects Studied.............................41

\section{Tables}

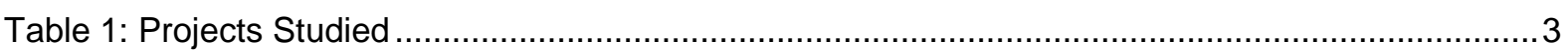

Table 2: Project Groupings and Unit Costs \$/tpa......................................................................

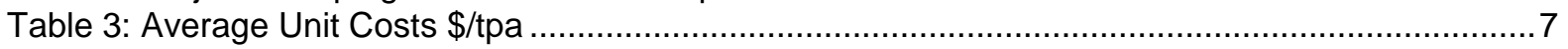

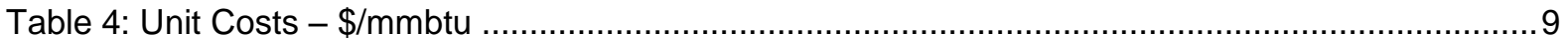

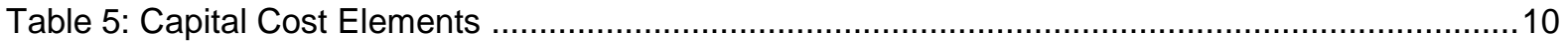

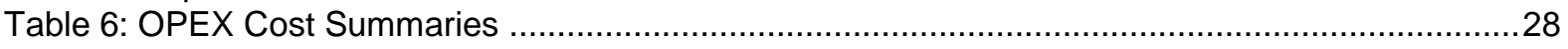

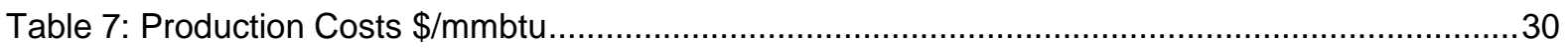

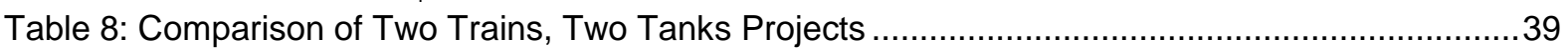

Table 9: Comparison of Three Trains, Three Tanks Projects ......................................................... 41 

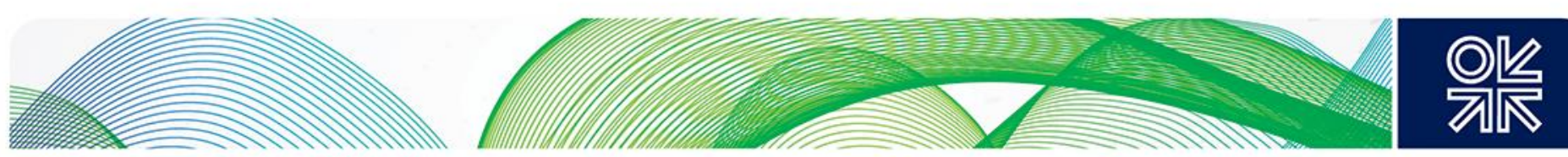

\section{Glossary}

bar $\mathrm{g}$ - unit of pressure close to 1 atmosphere

bcfd - billion cubic feet per day: a flowrate or production output of typically natural gas commonly used in North America

Brownfield - a plant built on an existing site

Capex or CAPEX - industry term for capital expenditure

$\mathrm{CO}_{2}-$ carbon dioxide

Debottlenecking - increasing plant capacity by removing low-cost production constraints

EPC - engineering, procurement and construction

FEED - front-end engineering design

FID - final investment decision: typically made by the investors in an LNG project when all necessary sales contracts and other government and regulatory approvals are in place

FLNG - floating LNG liquefaction vessel

FPSO - floating production storage and offloading vessel

Greenfield or Grassroots - new plant built on a new site

Lean gas - feed gas with a very low LPG and condensate content, essentially methane and ethane; typically a pipeline-quality gas

LNG - liquefied natural gas

$m^{3}-$ cubic metres

$\mathrm{m}^{3} / \mathrm{h}$ - cubic metres per hour

Mmscfd or mmscfd - millions of standard cubic feet per day

mtpa - millions of tonnes per annum

Opex or OPEX - industry term for operating expenditure

Qmax - Q-Max or Qatar Max: large LNG tanker with 266,000 $\mathrm{m}^{3}$ storage capacity

Qflex - Q-Flex or Qatar Flex: large LNG tanker with 210,000-216,000 $\mathrm{m}^{3}$ storage capacity

Rich gas - feed gas containing LPG and condensate; typically associated gas from oil production or a gas condensate field

$\mathrm{t} / \mathrm{h}$ - tonnes per hour

tpa - tonnes per annum

$\$$ - US dollar

$\$ /$ tpa - unit cost of production expressed as $\$$ per tonne per annum

$\$ / m m b t u$ - unit cost of production expressed as $\$$ per million btu per annum

$\$ \mathrm{~m}-$ millions of US dollars 

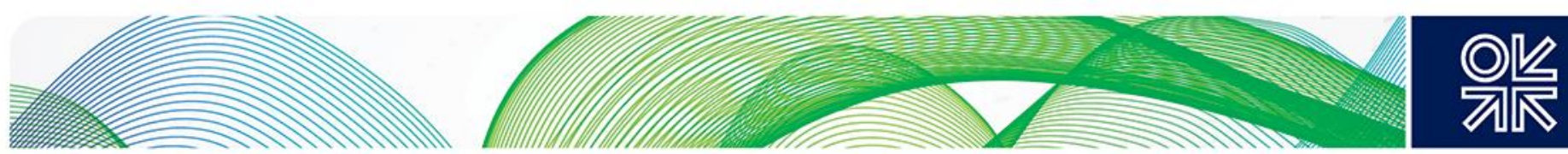

\section{Chapter 1. Context and Reason for Paper}

The capital cost of LNG liquefaction plants has been falling significantly since the highs of plants built during 2010-14. Figure 1 shows the cost of liquefaction plants constructed during 2014-18 overlaid with the cost of the upstream facilities that deliver the gas to the plant. It is the total project cost that drives the cost of LNG delivered by the plant.

Figure 1: Overall Project Capital Costs $\$$ /pa Constructed 2014-18

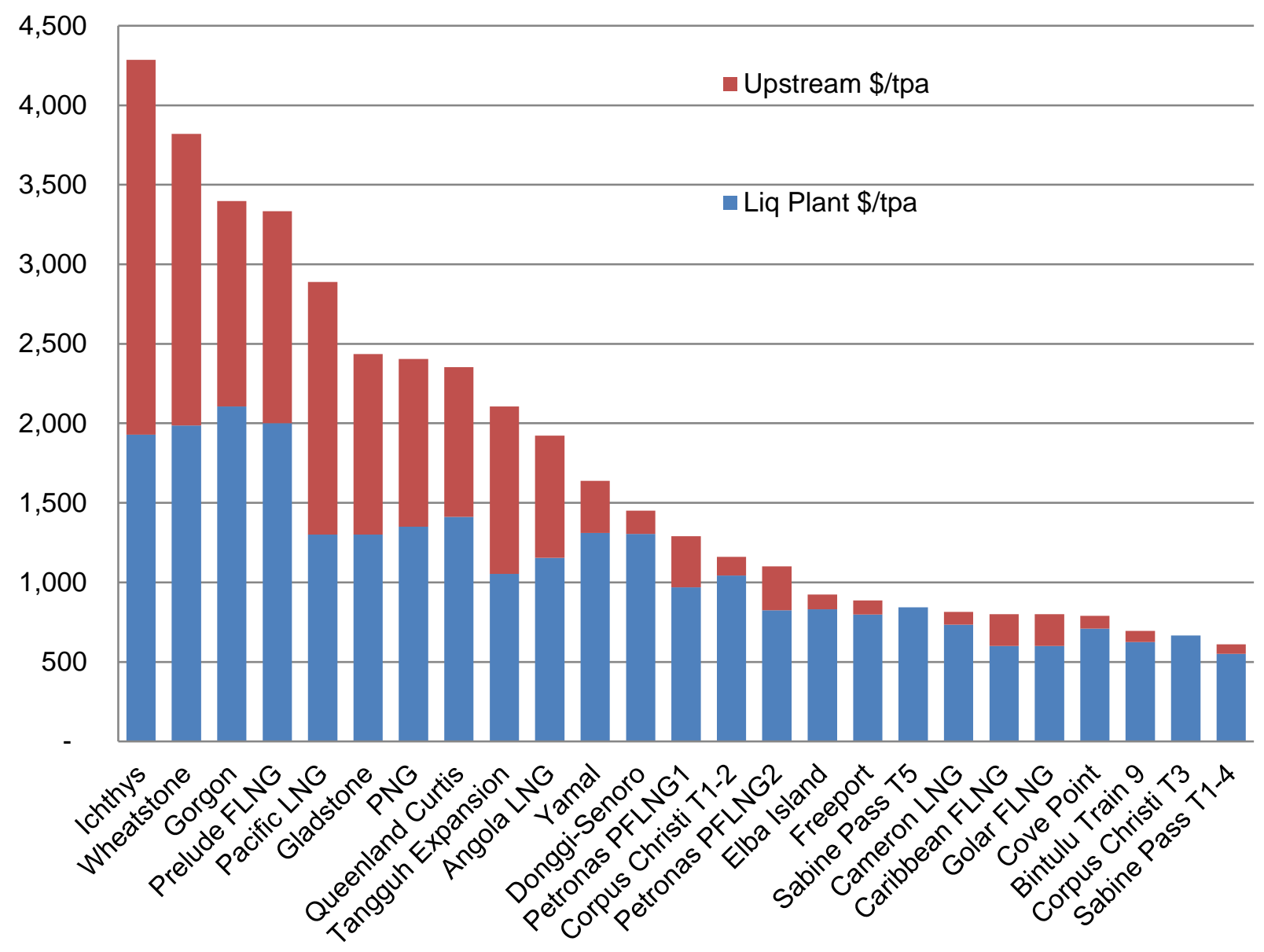

Collated by author from published data (refer to Appendix 1)

The major projects executed during 2010-14 were located in remote locations and included four FLNG projects. Over 50 per cent of the $90 \mathrm{mtpa}$ committed during this period occurred in Australia, which experienced a shortage of labour, raising construction costs to a new all-time high and a very strong Australian dollar compared with the US dollar on which the original budgets and final investment decisions were based. These increased costs not only affected the liquefaction plants but also the cost of the upstream facilities, including different technologies such as coal seam gas.

As shown, liquefaction plant costs have fallen from the highs of $\$ 2,000 /$ tpa to $\$ 600-1,400-a$ reduction of 30 to 50 per cent or more, which is excellent news for keeping the cost of LNG competitive. These reductions are also in line with the capital cost of other oil and gas facilities as 

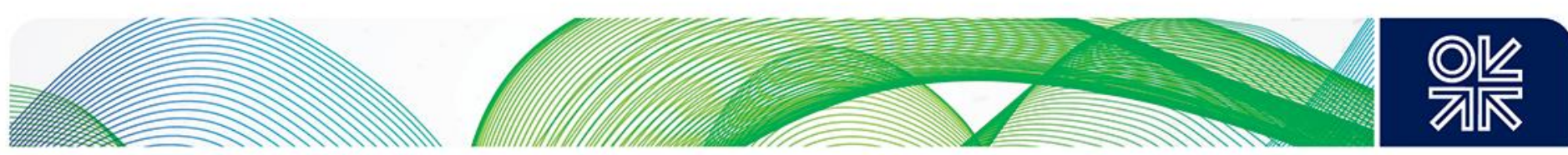

reported by the IHS Capital Cost Index ${ }^{1}$ as shown in figure 2, probably due to the downturn in the industry due to reduced investment at lower energy prices which increased competitive pressures on contractors and equipment suppliers.

\section{Figure 2: IHS Capital Cost Index}

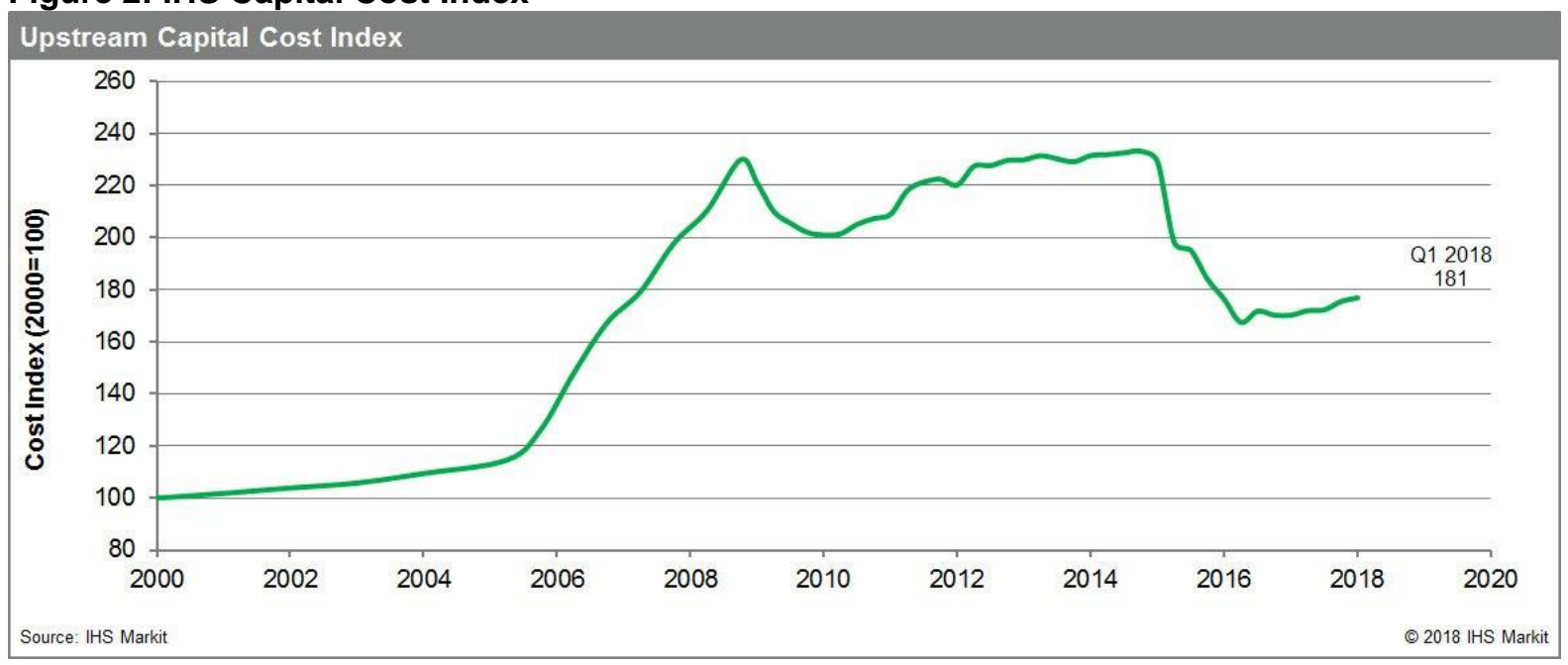

Source: Courtesy of IHS Markit

\section{Upstream Costs}

The cost of producing LNG also needs to include the cost of the upstream facilities to deliver the feed gas to the liquefaction plant. These costs are shown in figure 1 as an overlay on the liquefaction plant costs.

Upstream costs are driven by the scope of the facilities required to treat and transport the gas from the reservoir to the liquefaction plant. In the case of Ichthys this is extensive, with a major offshore FPSO and an $890 \mathrm{~km}$ pipeline to shore. The cost of the offshore pipeline has been stated at around \$2bn (\$250/tpa) and this cost could have been eliminated if a floating LNG plant had been used. Based on the quoted costs for FLNG, this may have offered a cheaper option than an onshore plant, albeit multiple units would have been required.

At the other extreme are the USA plants, which only require relatively short interconnecting lines to transport pipeline quality gas ${ }^{2}$ from the natural gas pipeline system. USA liquefaction plants up to now rely on a wide independent network of pipelines and gas supply sources outside of the operational and financial control of the liquefaction plant venture, and shareholders pay a significantly higher feed gas price than a conventional integrated LNG project. While USA gas prices are relatively low in the context of world gas prices, based on the Henry Hub they are volatile. Some new USA LNG projects are seeking to reduce this feed gas volume and price risk by vertically integrating dedicated upstream assets as part of their overall LNG project.

\section{Reason for this Paper}

This paper sets out to:

- $\quad$ analyse the recent reported costs

- understand why these costs have fallen

- understand what has driven this fall 

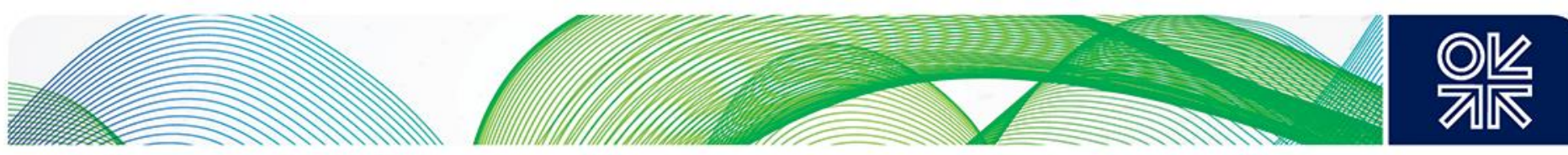

- establish whether further cost reductions likely in the future

- consider what are the enabling tools that could make that happen

- and consider what are the likely costs for upcoming liquefaction plants.

\section{Methodology}

This paper has been prepared by analysing the published data of the 23 projects constructed during 2014-18. These projects are listed below and their data and references are included in Appendix 1.

\section{Table 1: Projects Studied}

\begin{tabular}{|c|c|}
\hline USA & SE Asia \\
\hline Freeport & PNG \\
\hline Corpus Christi & Donggi-Senoro \\
\hline Cameron LNG & Tangguh Expansion \\
\hline Cove Point & Petronas PFLNG1 \\
\hline Sabine Pass & Petronas PFLNG2 \\
\hline Elba Island & Bintulu Train 9 \\
\hline & \\
\hline Australia & Africa \\
\hline Gorgon & Angola LNG \\
\hline Prelude FLNG & Golar FLNG \\
\hline Wheatstone & Russia \\
\hline Ichthys & Yamal \\
\hline Queensland Curtis & \\
\hline Gladstone & Not Yet Allocated \\
\hline Pacific LNG & Caribbean FLNG \\
\hline
\end{tabular}

In addition to the plants constructed or being constructed, many potential projects have been costed at the FEED stage but not yet been approved, and show many of the same trends in lower costs. The Canadian British Columbia projects have been estimated at approximately $\$ 1300-1500 /$ tpa and East Africa at $\$ 1250 / \mathrm{tpa}^{3}$. 

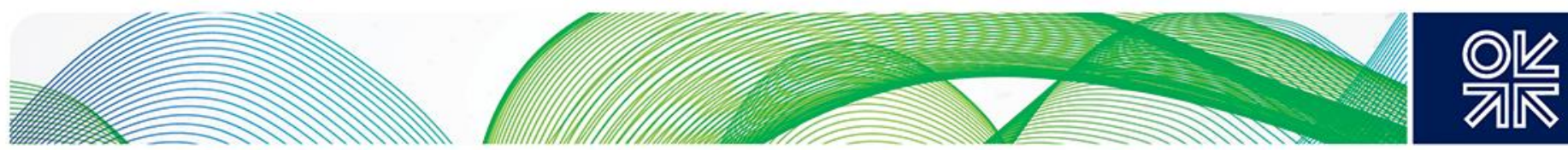

\section{Chapter 2. Review of Recent Cost Trends (2014-18)}

Figure 3 shows the costs of the LNG liquefaction plant component of the project costs shown in figure 1. Showing the liquefaction cost only enables a more meaningful comparison to be made. The upstream costs are specific to that development and can range from a simple low-cost tie-in to a gas pipeline network as in the USA, to a high-cost deep-water offshore development such as Ichthys.

Figure 3: Liquefaction Plant Capital Costs $\$$ /tpa Constructed 2014-18

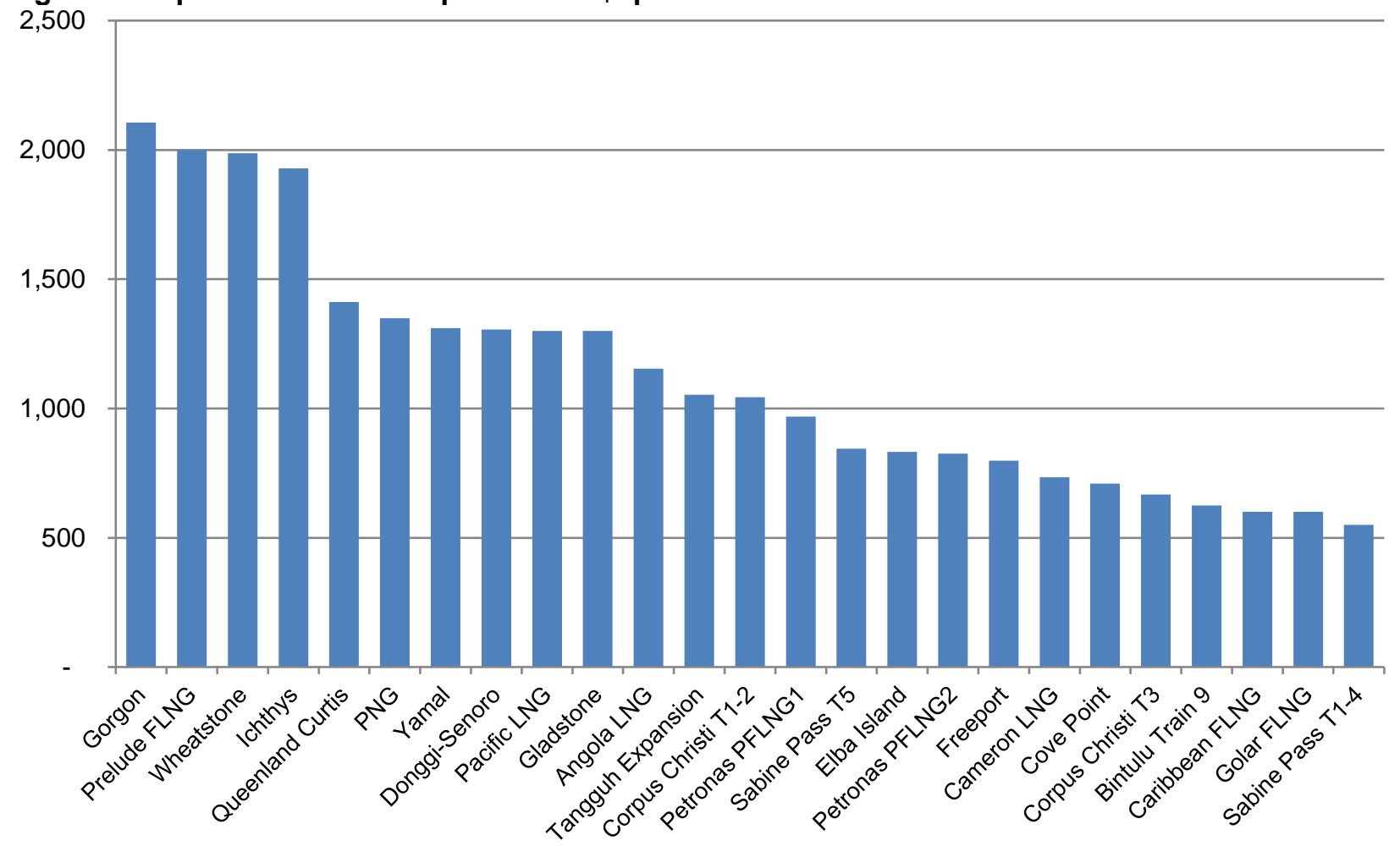

Source: Collated by author from published data (refer to Appendix 1)

From the review of figure 3 the following observations can be made:

- The Queensland plant costs (Queensland Curtis, Gladstone and Pacific LNG) are considerably lower than those located in NW Australia (Gorgon, Wheatstone and Ichthys). In part this is probably due to: 1) Queensland being less remote than the NW Australian plants; 2) processing lean coal seam gas compared with rich associated gas in NWA, which require additional facilities for gas liquids recovery; and 3) probably being constructed later than NWA when labour rates were reducing. However, another factor for the lower costs is probably the economies of scale. All three Queensland plants were built by the same contractor, using the same process technology and more or less in the same time frame. It is likely that these costs could have been reduced further if the plants had been combined on a single site with shared common facilities - for example jetties, storage tanks and utilities.

- Gorgon, with the highest unit cost, is a special case as a result of environmental sensitivity necessitating $\mathrm{CO}_{2}$ sequestration, as well as being located on a remote island. The scope also included a domestic gas plant and pipeline. 

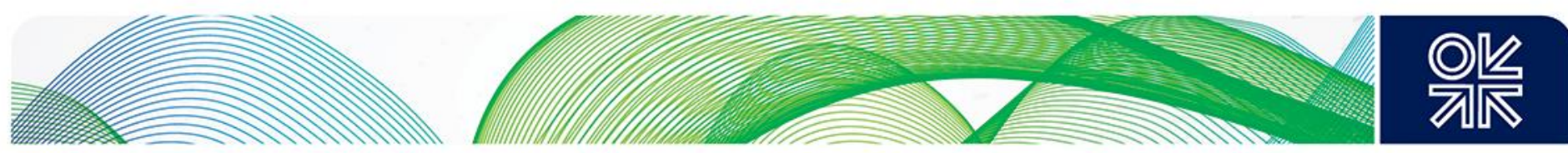

- Ichthys, also with a higher cost, uses a higher CAPEX combined cycle power plant which added complexity. The project ran into cost overruns ${ }^{4}$.

- It should be noted that when comparing Australian project costs with the rest of the world, Australian projects also carry the additional cost of quarantine for all imported equipment.

- The Yamal plant in northern Russia is cost competitive considering it was built in the hostile Arctic environment. Not only is it competitive, but Novatek have stated that they expect the cost of the next phase to be significantly lower by building the modules locally, albeit this is being challenged. It has been stated that the low arctic temperatures increase the performance of the plant, increasing production and thereby reducing unit costs. Special issues relating to construction in a permafrost environment will be eliminated by the use of a concrete gravity-based structures for the next phase.

- The cost of the Queensland, Papua New Guinea, Yamal, Donggi-Senoro and Tangguh (Indonesian) plants are all in the range of $\$ 1,000-1,400 / \mathrm{tpa}$, which was the industry unit cost used in 2010 prior to the high-cost Australian era. It could be stated that costs have returned to where they were at the start of the decade.

- The cost of the USA plants in Texas, Louisiana and Maryland are even lower at $\$ 700$ $1,000 /$ tpa and set a new benchmark for the industry. The reason for this is a combination of three features creating a low-cost 'sweet spot' that will be difficult to beat elsewhere.

1. Sabine Pass, Cameron and Cove Point liquefaction facilities were added to the existing import terminals, thus taking advantage of the existing LNG storage and jetties which can represent up to 50 per cent of a new plant cost. This is demonstrated by comparing Sabine Pass at $\$ 610 /$ tpa with Corpus Christi at $\$ 1,040 /$ tpa which is a greenfield site requiring new tankage, jetties and utilities.

2. The owners are utility companies and not international oil companies and use a more functional approach for the design, procurement and construction of the plants. This enables the use of suppliers' industry standard equipment rather than bespoke client equipment. Major international oil companies have developed very specific standards based on their extensive experience which are typically very demanding, and frequently require equipment suppliers to modify their standard plant, adding significant cost. Some suppliers have stated that they often have to strip down their standard plant and rebuild it to meet these bespoke requirements, adding 20 to 50 per cent to the cost. This not only affects the cost but also extends the schedule.

3. There are economies of scale from building multiple trains sequentially. Not only does this save engineering costs, but it enables single-purchase orders to be placed for multiple items, thus reducing prices - again an economy of scale. This sequential approach also allows for the efficient use of construction staff by moving them on from one train to the next, enabling continuity and bringing all the lessons learnt from the previous train to ensure more efficient working.

- This multiple train approach was used very effectively on Egyptian LNG Idku trains 1 and 2, where the trains were completed within 6-12 months of each other, taking full advantage of the synergies. Nigeria LNG Plus (trains 4 and 5) also demonstrated the benefit of successive site expansions capitalizing on improved infrastructure, and local and international experience. This enabled a doubling of plant capacity with a 50 per cent reduction in $\$ /$ tpa for the additional capacity.

4 'Ichthys LNG project costs blow out further':

https://www.Ingindustry.com/liquefaction/08022018/ichthys-Ing-project-costs-blow-out-further/ 

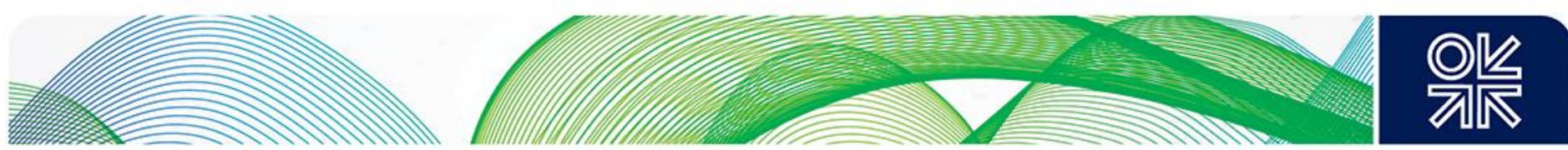

- The USA plants are processing treated lean pipeline gas, eliminating the need for extensive gas processing and liquids recovery, and requiring only minimal acid gas treatment as typically required for associated (rich) gas. However, while this reduces the project scope and capital cost, project value is normally enhanced by producing natural gas liquids with a higher value which offsets the higher plant cost.

- Floating liquefaction (FLNG) has also come of age and offers a competitive liquefaction alternative for offshore fields due to the avoidance of an expensive subsea gas pipeline to shore, as well as taking advantage of lower shipyard fabrication costs. There are now five projects: Petronas PLNG1 is operating offshore Sarawak; Golar Episeyo is operating offshore in Cameroon and shipped its first cargo to China in May 2018; Prelude is on location and expected to start up in late 2018; Petronas PFLNG2 is currently under construction and expected to start production in 2020; and the first FLNG barge to be constructed, Caribbean FLNG, is still awaiting assignment. The Caribbean FLNG relies on an FSU for storing tankersize shipments.

- The costs of the Petronas, Golar and Caribbean FLNGs appear to provide a competitive enabling technology for offshore gas fields by reducing the overall investment and enabling independent E\&P producers to monetize gas reserves using a leased LNG floating gas treatment unit (FPSO) business model. Prelude is a considerably more complex and expensive facility producing 5.3 mtpa of combined condensate, LPG and LNG production with the ability to stay on location during category 5 winds. Shell invested 20 years of development and over 1.6 million man-hours of engineering and design to develop a range of project realizations the benefits which they believe will become more evident with successive project implementations. Shell's approach was 'design one and build many's. 

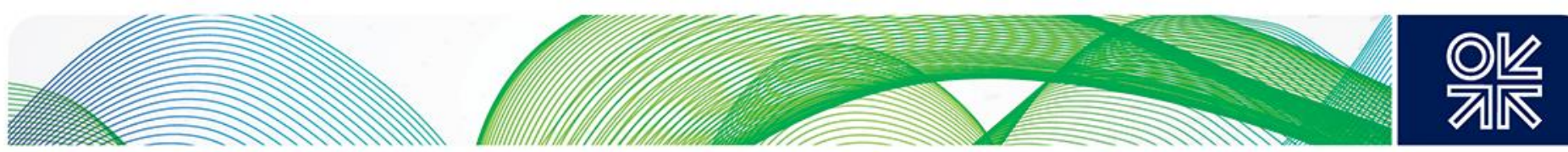

\section{Chapter 3. Unit Costs}

Table 2 groups the projects studied by location, brownfield or greenfield and feed gas type together with the unit costs calculated for each project studied. A breakdown of the costs is included in Appendix 1. Table 3 shows the average costs.

Table 2: Project Groupings and Unit Costs \$/tpa

\begin{tabular}{|c|c|c|c|c|}
\hline \multirow{2}{*}{ Location } & \multicolumn{2}{|c|}{ Brownfield (Expansions) } & \multicolumn{2}{|c|}{ Greenfield } \\
\hline & Lean Gas & Rich Gas & Lean Gas & Rich Gas \\
\hline Australia & & & $\begin{array}{c}\text { QC } 1412 \\
\text { Gladstone } 1291 \\
\text { Pacific } 1300\end{array}$ & $\begin{array}{c}\text { Gorgon } 2100 \\
\text { Wheatstone } 2000 \\
\text { Ichthys } 2000\end{array}$ \\
\hline Remote & Bintulu T9 625 & Tangguh T3 1053 & PNG 1349 & $\begin{array}{l}\text { Donggi } 1305 \\
\text { Yamal } 1311 \\
\text { Angola } 1154\end{array}$ \\
\hline USA & $\begin{array}{c}\text { Freeport } 799 \\
\text { Cameron } 733 \\
\text { Cove Point } 710 \\
\text { Elba } 832 \\
\text { Sabine Pass } 603 \\
\text { Corpus T3 } 667\end{array}$ & & Corpus T1-2 1044 & \\
\hline FLNG & - & - & $\begin{array}{c}\text { Golar } 600 \\
\text { PFLNG1 } 968 \\
\text { PFLNG2 } 825 \\
\text { Caribbean } 600\end{array}$ & Prelude 2000 \\
\hline
\end{tabular}

Source: Collated by author from published data (refer to Appendix 1)

Table 3: Average Unit Costs \$/tpa

\begin{tabular}{|c|c|c|c|c|}
\hline \multirow{2}{*}{ Location } & \multicolumn{2}{|c|}{ Brownfield (Expansions) } & \multicolumn{2}{|c|}{ Greenfield } \\
\hline & Lean Gas & Rich Gas & Lean Gas & Rich Gas \\
\hline Australia & 1050 & 1350 & 1550 & 2000 \\
\hline Remote & 900 & 1050 & 1350 & 1500 \\
\hline USA & 700 & $\mathrm{~N} / \mathrm{A}$ - shale gas & 1050 & $\mathrm{~N} / \mathrm{A}$ - shale gas \\
\hline FLNG Bespoke & \multirow{2}{*}{\multicolumn{2}{|c|}{$\begin{array}{l}\mathrm{N} / \mathrm{A} \text { - not realistic to expand FLNG. } \\
\text { Replace with larger unit or add second } \\
\text { unit. }\end{array}$}} & 900 & 2000 \\
\hline FLNG Functional & & & 600 & $\begin{array}{c}\mathrm{N} / \mathrm{A} \text { - rich gas will } \\
\text { be bespoke }\end{array}$ \\
\hline
\end{tabular}

Source: Collated by author from published data (refer to Appendix 1) 

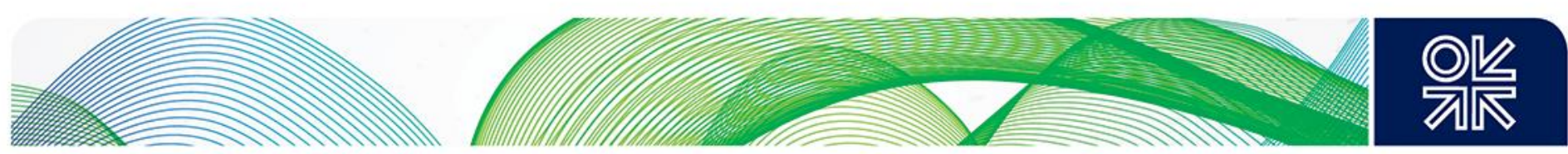

The average costs in table 3 have been calculated on the following basis:

- The Queensland Curtis (QC), Gladstone and Pacific LNG plants were built at the same time and the cost of $\$ 1300-1400 /$ tpa reflects an economy of scale. A more realistic cost for a single unit would likely be 10 to 20 per cent higher at 1500-1600, and an average of $\$ 1550 /$ tpa is proposed.

- Gorgon is slightly more expensive as it was a complex project on a remote island and included $\mathrm{CO} 2$ sequestration. Wheatstone and Ichthys are more representative. On this basis, $\$ 2000 /$ tpa is more representative of this group.

- Bintulu train 9 is listed as remote as it is located on Sarawak. However, it is an industrialized site with eight existing LNG trains and good access to efficient labour resources and probably more aligned with the USA costs. A unit cost of $\$ 900 /$ tpa is proposed for this group.

- $P N G$ is a clearly defined project, hence $\$ 1350 /$ tpa is realistic for this classification. An expansion is being planned.

- Regarding the Donggi, Yamal and Angola group, Angola is low at $\$ 1154 /$ tpa but was constructed in 2008-12 and only became fully operational in 2015 following modification. So the cost today would like be higher. Donggi, at $\$ 1305 /$ tpa, appears very competitive but was constructed on an existing oil export terminal site so some elements of brownfield. Yamal, at $\$ 1311 /$ tpa, is low as the production is enhanced by the lower arctic temperatures reducing the unit cost. So a higher figure of $\$ 1500 /$ tpa is suggested for this group.

- The USA expansion projects show close alignment, and the average of $\$ 700 / \mathrm{tpa}$ is representative of this group.

- The first phase of Corpus Christi, comprising trains 1 and 2 and associated storage and infrastructure at $\$ 1041$, is 50 per cent higher than the train 3 expansion. This aligns well with the additional cost of storage, jetty and infrastructure needed for a greenfield plant. So $\$ 1050$ is representative for this group.

- Regarding the FLNG costs, Golar is a standard functional leased unit, whereas Petronas PFLNG 1 and 2 are bespoke units, which explains the higher costs. The cost of PFLNG2 is lower as the contract was awarded as an extension of PFLNG1 contract and took advantage of the weak fabrication market. Unit costs of $\$ 600 /$ tpa for a functional unit and $\$ 900 /$ tpa for a bespoke unit are proposed. Prelude is regarded as a special case and a development project, and future unit costs are expected to be lower.

- The figures in italics are pro-rated using the following factors:

- brownfield to greenfield add 50 per cent for tanks, jetty and utilities

- lean gas to rich gas add 10 per cent $^{6}$ for the gas liquids equipment; however, this does not apply for Australia as lean gas plants are in Queensland with a lower construction cost base than the remote NW Shelf

Table 4 lists the costs expressed as $\$ /$ mmbtu 7 .

\footnotetext{
${ }^{6}$ Refer to Appendix 4

${ }^{7}$ Using conversion of $0.035 \%$
} 

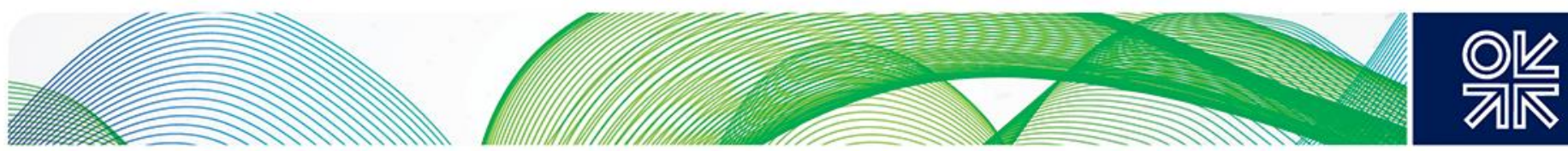

Table 4: Unit Costs $-\$ / m m b t u$

\begin{tabular}{|c|c|c|c|c|}
\hline \multirow{2}{*}{ Location } & \multicolumn{2}{|c|}{ Brownfield (Expansion) } & \multicolumn{2}{|c|}{ Greenfield } \\
\hline & Lean Gas & Rich Gas & Lean Gas & Rich Gas \\
\hline Australia & 3.7 & 4.7 & 5.4 & 7.0 \\
\hline Remote & 3.2 & 3.9 & 4.7 & 5.3 \\
\hline USA & 2.5 & $\mathrm{~N} / \mathrm{A}$ - shale gas & 3.7 & $\mathrm{~N} / \mathrm{A}$ - shale gas \\
\hline FLNG Bespoke & \multirow{2}{*}{\multicolumn{2}{|c|}{$\begin{array}{l}\mathrm{N} / \mathrm{A} \text { - not realistic to expand FLNG. } \\
\text { Replace with larger unit or add second } \\
\text { unit. }\end{array}$}} & 3.2 & 7.0 \\
\hline FLNG Functional & & & 2.1 & $\begin{array}{c}\text { N/A - rich gas will } \\
\text { be bespoke }\end{array}$ \\
\hline
\end{tabular}

Source: Collated by author from published data (refer to Appendix 1) 

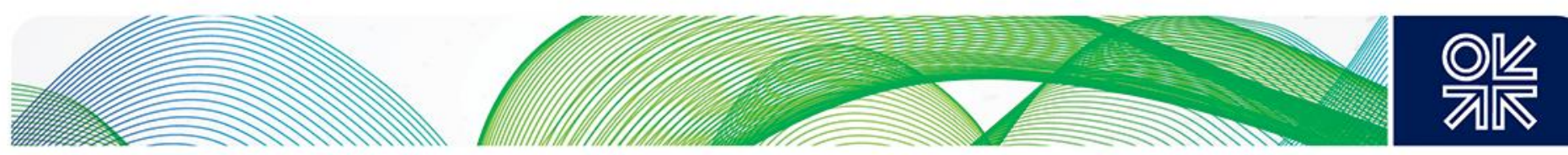

\section{Chapter 4. Main Cost Factors}

Chapter 3 presented the unit costs for the project studied and suggested modified average values for estimating the cost of new plants. This chapter investigates what drives these costs to assist in better understanding how to estimate future plant costs.

Many developers are seeking to use a global $\$ /$ tpa unit cost to estimate future plant costs. While this is fine for normalizing the capacity, it is not realistic for complexity and location factors as they can be very different. These must be taken into account when looking at likely project development costs. This chapter determines and suggests factors that could be used.

The cost of liquefaction plants is driven by three main factors:

- Capacity - production rate ${ }^{8}$.

- Complexity - in other words, plant scope needed to process either lean gas or rich gas and in some case $\mathrm{CO}_{2}$ sequestration' ${ }^{9}$. Some plants use more complex combined cycle power plants, such as Ichthys and Tangguh rather than lower capital cost open cycle units.

- Location - remote or developed, greenfield or brownfield.

\section{Cost Elements}

The capital cost of a liquefaction plant is typically broken down into the following elements, ${ }^{10}$ as shown in table 5 :

Table 5: Capital Cost Elements

\begin{tabular}{|l|c|l|}
\hline Component & & Remarks \\
\hline Owner's costs & $10 \%$ & Client costs mainly home office \\
\hline $\begin{array}{l}\text { Engineering and project } \\
\text { management }\end{array}$ & $8 \%$ & EPC contractor costs mainly home office \\
\hline Equipment & $30 \%$ & Numbered items costs \\
\hline Bulk materials & $20 \%$ & Piping, instrumentation, electrical \\
\hline Construction & $32 \%$ & Labour + construction bulks, e.g. concrete \\
\hline
\end{tabular}

\section{Owner's Costs}

Owner's costs are generally not capacity, complexity or location specific. This cost relates to the home office team and specialist consultants overseeing the development of the project and the design and construction by the EPC contractor. Regarding capacity, the same sized team will generally be used as a larger capacity normally requires multiple identical trains, more identical tanks and possibly a further jetty or jetty head. For a more complex process the impact will also be minimal - perhaps a few more specialists. For a difficult location a slightly larger team may be required with higher travel and accommodation costs.

\section{Engineering and Project Management}

These costs are similar to the owner's costs. They are not in direct proportion to the production rate, as multiple trains and tanks are used, and the drawings and specifications will be copies, and single purchase orders will be used to order multiple items or award subcontracts. The site project management component may increase slightly for a remote and difficult location due to increased travel and accommodation costs at site.

\footnotetext{
${ }^{8}$ Normally expressed as millions of tons per annum mtpa

${ }^{9}$ Installed at Gorgon and Snøhvit

10 'LNG Plant Cost Escalation': https://www.oxfordenergy.org/publications/lng-plant-cost-escalation/
} 

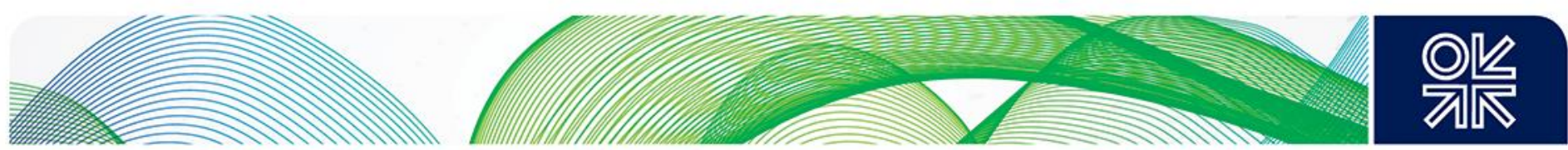

\section{Equipment and Bulk Material Costs}

These will increase with production rate, in other words, two trains will require double the number of items and bulk materials. The cost of the tanks and the jetty will also be dependent on the number and the size. However, equipment and material costs are not directly location specific, in that process plants are basically very similar and supplied by the same international fabricators. Only the shipping costs are likely to be different for a remote and difficult location. A specific example of this is the Australian projects, where all the equipment had to be quarantined, adding considerable cost.

\section{Construction Costs}

These are capacity, process complexity and location dependent. Regarding capacity, multiple units, while copies, still have to be constructed separately. More complexity means constructing more equipment. Regarding location, a remote and difficult site will typically require a construction camp, possibly an airstrip and harbour and often a new township. Other factors can also affect construction costs, such a limited resources, as experienced during the Australian projects where construction costs reached an all-time high due to many projects being constructed at the same time. The use of modular plant in remote and difficult locations adds considerable structural steel and transportation costs but can be offset by high unit labour costs.

Another cost that is location dependent is the site preparation phase. The can be complex and costly in terms of time. An example is the Nigerian LNG projects, which required the swamp to be preloaded for 18 months with rock to provide a stable foundation. Another is the Peru LNG, where solid rock terraces were blasted for plant construction.

\section{Factors}

\section{Capacity Factor}

As the costs in this paper are unit costs, i.e. \$/tpa, the capacity factor is 1 , in other words, the costs are normalized. The cost of a plant is calculated by multiplying the unit cost by the capacity. Capacity considerations are discussed further in Appendix 3.

\section{Complexity Factor}

This factor adjusts for the process complexity, for example lean gas processing to produce just LNG as a product, or rich gas producing LPG and condensate. Based on the analysis in Appendix 5 these have been estimated as shown in figure 4, which shows that rich gas plants cost 10 per cent more than lean gas plants. This is an average figure based on the projects studied in this paper, and LPG and condensate production will vary project by project.

\section{Figure 4: Complexity Factors}

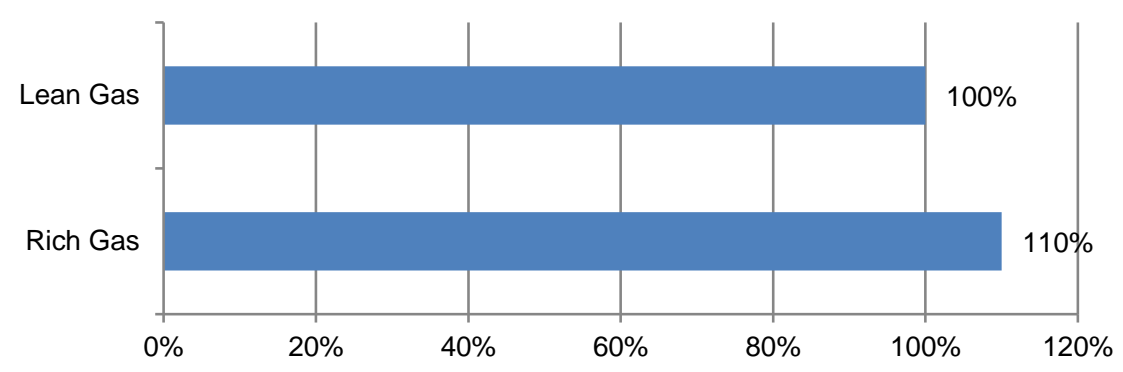

Source: By authors based on analysis of published data, refer Appendix 5 

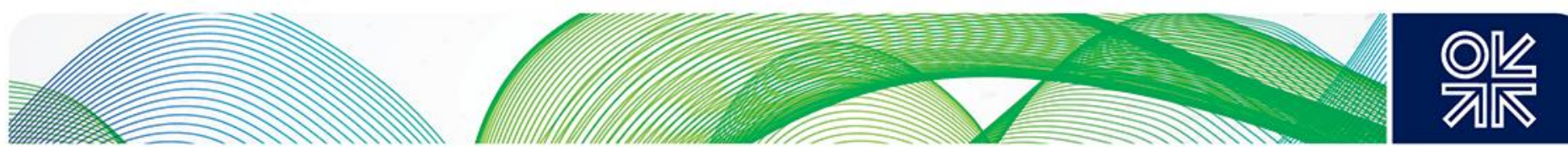

\section{Location Factor}

This adjusts for the cost of construction at different locations and is a combination of labour rates and labour efficiency. The industry typically estimates for this using Lang Factors 11 where the USA Gulf Coast is 1 and the cost at other locations are estimated using multipliers. Based on the unit costs of the projects studied in this paper location factors have been estimated as shown in figure 5 . The analysis of these factors is included in Appendix 4.

This would indicate that location factors can be summarized as 3 main groups:

- USA 100 per cent (base case)

- Remote Locations 130 per cent (30 per cent uplift)

- NW Australia 170 per cent (70 per cent uplift)

Figure 5: Location Factors

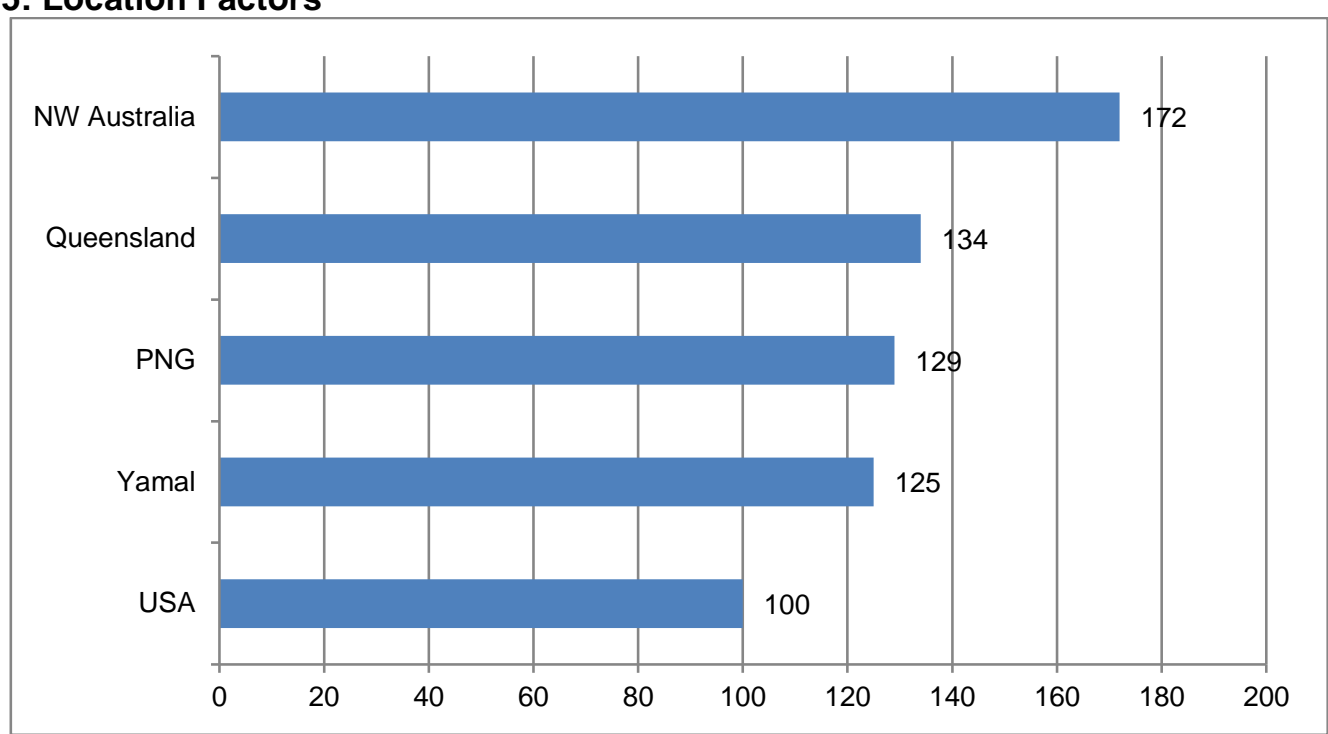

Source: By author based on analysis of published data (see Appendix 4)

\section{Estimating Plant Costs:}

In summary the cost of a greenfield liquefaction plant can be estimated as follows:

\section{Unit Cost $=$ USA Lean Gas Cost 1050 x Complexity Factor $x$ Location Factor}

Example: rich gas plant located in NW Australia would cost USA lean $\$ 1050$ (table 1) x Complexity 110 per cent (figure 5) $x$ Location 172 per cent (figure 5) = $\$ 2000 /$ tpa, in other words the Wheatstone and Ichthys costs in table 1.

For a brownfield expansion the following would apply:

\section{Unit Cost $=$ USA Lean Gas Cost $700 \times$ Complexity Factor $x$ Location Factor}

Example: additional lean gas train located in PNG would cost $700 \times 100 \% \times 130 \%=\$ 910 /$ tpa

\footnotetext{
11 'Updating the Lang Factor and Testing its Accuracy, Reliability and Precision as a Stochastic Cost Estimating Method' https://pmworldjournal.net/wp-content/uploads/2014/10/pmwj27-oct2014-Wain-updating-the-lang-factor-Featured-Paper.pdf
} 

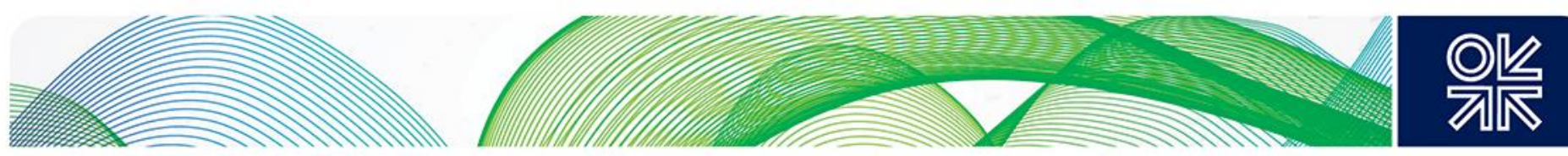

\section{Chapter 5. Opportunities for Further Cost Reduction}

In addition to capacity, complexity and location, other considerations drive plant costs, including:

- design basis

- specifications

- process selection

- contract execution strategy

- permitting and environmental factors.

These are discussed in the following sections with suggestions for some of the topics on how costs could be reduced for future developments.

\section{Design Basis}

\section{Concept Selection}

The correct concept must be established at the outset of the project. The concept selection study is a very low-cost activity compared with the cost of the later stages. Concept selection should consider all options and take full advantage of new enabling technologies to reduce costs.

Opportunity for cost reduction: Ensure that the decision to build multiple trains is taken at the planning stage and structured into the FID and procurement chain process to maintain continuity. The decision to repeat a train after the project has been completed and demobilized will not realize the same cost savings.

\section{Plant Location}

While this is determined by the location of the gas field or supply pipeline there are opportunities to reduce costs.

Opportunity for cost reduction: Consider the use of floating liquefaction units for offshore field development to avoid the cost of pipelines to shore and possible permitting issues for difficult and new locations where there are not established procedures in place. ENI's decision for FLNG Coral South is an example.

If possible, seek a plant site that is in an industrial area with an efficient and cost-effective work force. This may involve removing the gas liquids close to the wellhead and piping the lean gas to a separate site. Another option for high-cost or remote areas is to use a pre-fabricated process barge or FLNG unit.

\section{Plant Capacity}

The most important cost driver is the plant capacity (production rate) normally expressed at millions of tons per annum - mtpa.

However, while the process plant cost is a direct function of capacity, the tankage and offloading facility costs are not. Tankage and jetty head requirements are a stepwise addition determined by shipping frequency.

- One-train, 4-5 mtpa plant will require 1 tank and 1 jetty with 1 jetty head.

- Two-train, 8-10 mtpa plant will require 2 tanks and still 1 jetty.

- Three-train, 12-15 mtpa plant will still require only 2 tanks and 1 jetty but with 2 jetty heads. 

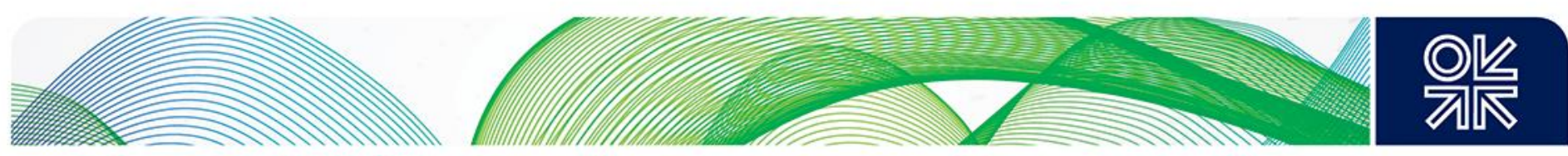

However, there are exceptions. For example, two tanks are often installed for a single-train plant where the addition of a second train is planned in the near term or where more storage flexibility is required.

Also, the length of the jetty is driven by water depth and in some cases a breakwater is required. These specific requirements add costs that are not related to capacity and will distort the unit cost. These features need to be taken into account when comparing costs.

This is also the case where a liquefaction train(s) is added to an existing facility, in other words, a brownfield development. In the case of many of the USA liquefaction plants, such as Sabine Pass, liquefaction trains are added to an import terminal utilizing the existing tanks and jetty. The same applies to liquefaction plant expansion projects, such as Tangguh train 2, Bintulu train 9.

Opportunity for cost reduction: The cost of an expansion is lower than a new site. The costs of a single-train greenfield project have a long payback time. Consider working in partnership with an existing plant owner to utilize any spare capacity in that plant. It is possible that the capacity of the existing plant could be increased by debottlenecking. The other option is to build a new liquefaction train adjacent to an existing plant owned by others and utilize the existing storage and export facilities.

An example of this is the Pluto train 2 expansion ${ }^{12}$

\section{Feed Gas}

These specify the feed gas composition(s) for the design of the plant over the life of the project. They are given for a particular reservoir or pipeline source. The pressure is critical as the higher the pressure the less power is required for liquefaction. Most plants seek a minimum of 80 bar. If the pressure drops, a feed gas compressor can be installed at a later date. Gas associated with oil production (associated gas) contains heavier hydrocarbons which are extracted and sold separately (NGLs and LPGs). Lean gas, such as pipeline gas or coal seam gas, is primarily methane and does not require heavy hydrocarbon removal.

Opportunity for cost reduction: The simplest plant processing lean gas offers the lowest cost. However, when value is considered the more valuable gas liquids normally offset the additional processing cost.

\section{Product Specification}

The industry is focused on two key values - nitrogen content and calorific value. As nitrogen has no heating value, the content in LNG needs to be kept to as low as reasonably possible and this is controlled normally by the end flash ${ }^{13}$. The other issue with nitrogen content is that it can cause stratification in the LNG storage and possible 'roll over'14. Maximum nitrogen content is normally specified as 1 per cent by mol.

The other value is heating value, which is controlled by the extraction of the heavier hydrocarbons, for example LPG by fractionation. LNG is sold with a range of heating values and the Japanese market prefers higher heating value LNG. A range of LNG specifications is attached in Appendix 3.

\section{Design Margins/Performance Guarantees}

Design margins ensure that a plant meets it production capacity and passes its performance guarantees. Design margins do add cost by increasing the size of the equipment and in some cases

\footnotetext{
12 'Woodside Crafts New LNG Expansion Plan After Striking Exxon Deal': https://www.bloomberg.com/news/articles/2018-02 13/woodside-plans-a-2-5-billion-raising-to-buy-exxon-s-scarborough

'State-of-the-art nitrogen removal methods from Air Products for liquefaction plants' http://www.airproducts.com/ /media/Files/PDF/industries/Ing/en-LNG-journal-paper.pdf

14 'Rollover in LNG Storage Tanks':

https://giignl.org/sites/default/files/PUBLIC AREA/Publications/rollover in Ing storage tanks public document low-res.pdf
} 

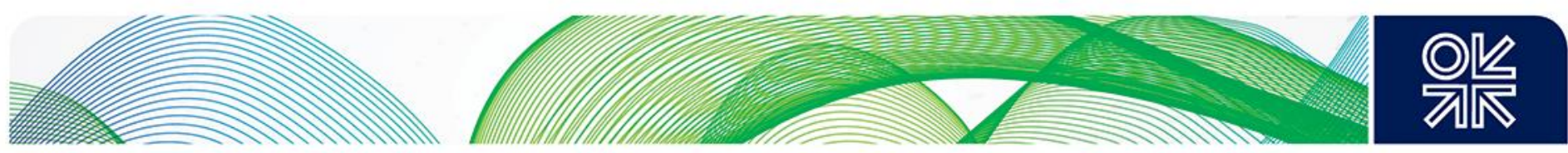

the pipe sizes. Design margins are typically 10 per cent. While this adds cost it can be recovered during a debottlenecking process to increase capacity at a later date.

Opportunity for cost reduction: Intelligent application of margins rather than a simple across the board approach. Discuss with vendors to get the correct balance of risk and reward.

\section{Train Size}

These generally fall into standard sizes based on the liquefaction process specified. Most owners specify the process based on their experience, in other words, they stay with the same process. The capacity is primarily driven by the compression power (often referred to as specific power). The APCI C3/MR plants typically produce $5 \mathrm{mtpa}$ and the CPOC $4 \mathrm{mtpa}$, albeit there are variations depending on the specific design condition, for example lower ambient temperature produces gas turbine power and better air-cooled heat exchanger performance leading to more LNG production. This is apparent with the Yamal plant ${ }^{15}$. ExxonMobil is looking to develop the Rovuma field in Mozambique using large 7.4 mtpa trains ${ }^{16}$, probably using the same AP-X process used in Qatar rather than the 5 mtpa trains originally planned by ENI. ExxonMobil quotes the advantages of delivering lower production cost through an economy of scale. One issue with larger trains is the higher loss of production in the event of a shut down.

Opportunity for cost reduction: For a greenfield project, select the optimum process for the project rather than just repeating previous projects. The larger the plant the better the economies of scale, and it is interesting to note that Exxon is considering large 7.6 mtpa trains similar to Qatar for Mozambique. However, for an expansion it is probably better to stay with same process due to familiarity and common sparing. Also consider other proven processes for new projects, for example 5 x 1.6 mtpa PRICO trains being proposed for Jordan Cove.

\section{Tank Size}

The industry norm has become $160,000 \mathrm{~m}^{3}$ full containment tanks. It is interesting to note that Cheniere has moved from lower cost single containment tanks used at Sabine Pass to more expensive full containment tanks at Corpus Christi. Full containment tanks are intrinsically safer and require a smaller plot space. The other variable is the size of the tanks, but only two liquefaction projects have used larger tanks: Darwin at 188,000 and Donggi-Senoro at 170,000. Larger tanks are used at import terminals with the largest above ground being 230,000 in Japan ${ }^{17}$. These very large tanks use 7 per cent nickel steel instead of the traditional 9 per cent, reducing the nickel cost considerably.

Opportunity for cost reduction: Optimize the size and number of tanks with capacity and ship size and frequency. There is an economy of scale in constructing larger tanks, and fewer tanks results in fewer tank pumps and individual tanks loading and unloading lines. Investigate the use of lower cost 7 per cent nickel steel. The use of Membrane tanks may also be an option for cost reduction.

\section{Ship Size}

The norm now is for LNG tankers with a capacity of $173,000 \mathrm{~m}^{3}$, although larger Qflex $(210-216,000)$ and Qmax tankers $(266,000)$ are operating for Qatar Gas exporting LNG from Qatar. Larger tankers require stronger jetties and more dolphins, adding to the cost.

Opportunity for cost reduction: Optimize ship size based on expected market. Be careful not to specify larger tankers unless required as this will increase jetty costs, for example Qflex and Qmax

\footnotetext{
15 'Novatek exploits Arctic temperatures for better gas liquefaction': https://fluidhandlingmag.com/display news/13542/novatek exploits arctic temperatures for better gas liquefaction/

16 'UPDATE 1-Exxon beefs up Mozambique LNG project to cut costs ahead of bank talks': https://af.reuters.com/article/africaTech/idAFL8N1U85X0

'Project to construct one of the world's largest LNG storage tanks' http://www.osakagas.co.jp/en/company/enterprise future/article2/
} 

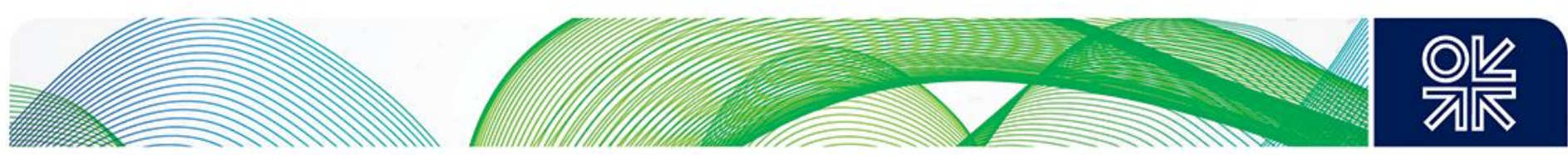

\section{Repeat Designs}

Expanding production by constructing repeat trains reduces costs. This is very evident in the USA where Sabine Pass has five identical trains and train 6 planned, and Corpus Christ has three. To obtain the maximum cost saving from this approach the trains must be identical and built sequentially to obtain the economy of scale. The approach of building two identical trains at the initial phase of a development is not new, as most projects typically specify two identical trains, or even three in the case of Gorgon and Yamal.

Opportunity for cost reduction: Stay with the concept of repeat designs. The industry could consider a standard 'off the shelf' design. This would require the feed gas pre-treatment to meet a standard specification.

\section{Greenfield or Brownfield}

It is much cheaper to add liquefaction trains to an existing facility than build from scratch due to the use of the existing infrastructure. This is demonstrated at Sabine Pass where the liquefaction trains were added to an existing import terminal at a cost of about $\$ 600 /$ tpa, compared with Corpus Christi which is a greenfield plant at $\$ 900 /$ tpa. This additional $\$ 300 /$ tpa covers the costs of the new tanks, jetty and utilities for the new site. Other examples of converting existing import terminals are Cove Point, Freeport LNG and Cameron LNG.

Opportunity for cost reduction: Choose a brownfield site if possible to take advantage of the existing infrastructure. Consider adding liquefaction facilities to a liquefaction plant owned by another operator.

\section{Driver Selection: Gas turbines, steam turbines or electric motors}

First-generation liquefaction plants used steam turbines to drive the refrigeration compressors. The industry then moved to industrial gas turbines and recently to aero-derivative gas turbines, which offer a smaller footprint, have a better fuel efficiency, lower emissions and are relatively simple to maintain. Only the Snøhvit plant has used all electric drives to date, although they are being considered for Freeport LNG ${ }^{18}$. Prelude FLNG uses steam turbines, but the future Shell FLNG Lean projects will use gas turbines. The Tangguh plant uses a combination of steam and gas turbines and electric motors, and this configuration has been repeated for the train 3 expansion.

Opportunity for cost reduction: Undertake a driver study and challenge any proposal not to use aero-derivative gas turbines which offer better fuel efficiency and lower emissions. Enable competition between the main suppliers, for example, GE, Siemens, Mitsubishi etc.

\section{Modular vs Stick-Built}

The choice will be driven by the location. Stick-built has been used for the recent plants in the USA as they are located in a highly developed oil and gas area with cost-effective construction. This stick-built approach is also likely for the proposed new plant in Qatar for the same reason. However, for remote locations such as NW Australia and Mozambique, modular construction is likely to be the quickest but not necessarily the cheapest, due to the large amounts of additional structural steelwork required for module transportation. Structural steel can typically represent 50 per cent of the module weight. Also, transportation costs are high. Novatek is considering alternatives for Arctic-2 to reduce the high costs of transportation from Asian construction yards.

Opportunity for cost reduction: Study the possibility of stick-built even for remote locations. Do not reject the idea immediately based on precedent. Look to construct modules locally to reduce

\footnotetext{
18 'American LNG Export Project': https://www.gepowerconversion.com/press-releases/freeport-Ing-selects-ge-major-northamerican-Ing-export-project
} 

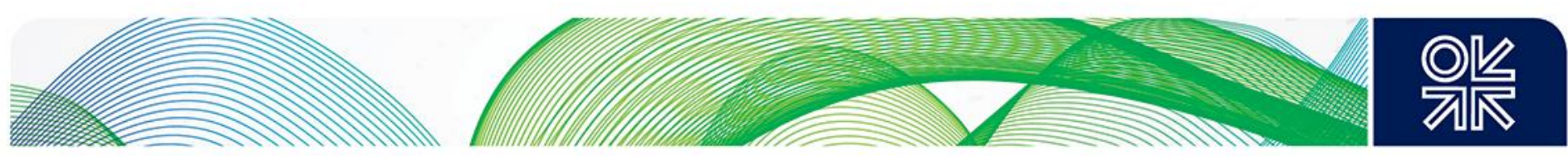

transportation costs and schedule, for example Novatek Arctic-2 is looking to develop local fabrication yards on the Yamal peninsula.

\section{Specifications}

\section{General Specifications}

These typically fall into two major groups:

- bespoke

- functional.

Major international energy companies have been operating LNG plants since the 1970s and have developed a wealth of knowledge which is reflected in bespoke company standards. However, these requirements add considerable cost to the project and are increasingly being used on a selective basis, with the companies trying to assess whether they do add value through applying a value engineering process ${ }^{19}$.

There is an increasing tendency to use functional specifications. These are often referred to as 'fit for purpose' and enable equipment and material suppliers to provide industry standard equipment, in other words, that accepted by the industry. It should be noted that all the major equipment suppliers have also developed a wealth of experience and this is reflected in what they supply. New plant owners tend to use functional specifications.

It has been stated that the use of bespoke specifications can add 20 to 50 per cent to the cost of equipment and materials. In extreme cases, manufacturers have stated that they have had to rebuild their standard equipment with bespoke materials, coatings, and control and instrumentation systems to meet very demanding specifications.

Opportunity for cost reduction: Use industry standard functional specifications and avoid client bespoke specifications where possible, as these add cost and extend the schedule.

\section{International Standards}

Most projects specify international standards for equipment and materials to enable the most competitive prices to be obtained from world-wide procurement. These typically include API for equipment and piping materials. An initiative is underway by the International Association of Oil and Gas Producers (IOGP) to standardize specifications ${ }^{20}$. The IOGP is formed of 17 major energy companies and plans to reduce equipment and materials costs by up to 50 per cent through standardization.

\section{National Standards}

Projects need to comply with local standards, which will be specified. Specific onerous requirements should be challenged as they may be taken out of context or misunderstood for an oil and gas project.

In the USA, LNG projects must comply with 49 CFR 193 'Liquefied Natural Gas Facilities: Federal Safety Standards'.

\section{International Codes and Practices}

The major international codes used for LNG projects are the USA standard NFPA $59 A^{21}$ 'Standard for the Production, Storage, and Handling of Liquefied Natural Gas (LNG)' and European standard

\footnotetext{
${ }^{19}$ https://en.wikipedia.org/wiki/Value engineering

20 JIP reaches standardization milestone': https://www.iogp.org/blog/international-standards/jip33/ijp-reaches-standardizationmilestone/

21 'Standard for the Production, Storage, and Handling of Liquefied Natural Gas (LNG)': https://www.nfpa.org/codes-andstandards/all-codes-and-standards/list-of-codes-and-standards/detail?code $=59 \mathrm{~A}$
} 

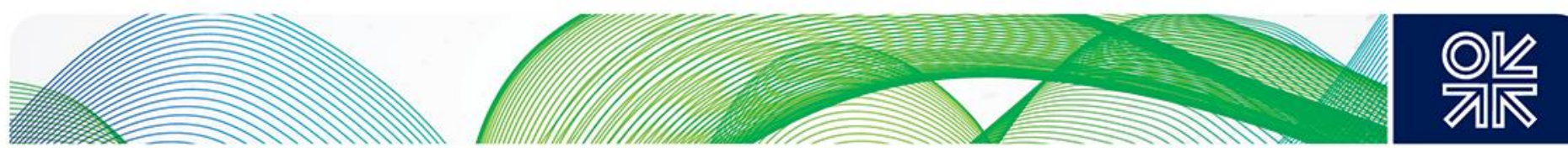

EN147322 'Installation and equipment for liquefied natural gas. Design of onshore installations'. USAled projects normally follow NFPA 59A and European-led projects follow EN1471, although there are exceptions. NFPA 59A is prescriptive, whereas EN1473 is a risk-based, case-by-case method. For projects outside of the USA and Europe the code will be decided by the developer in conjunction with the stakeholders. If the developer is USA based it will likely be NFPA 59A and if outside the USA then EN 1473.

However, it should be noted that when building an additional 'identical train' many years after the first train, the design codes and standards may have changed, leading to safety issues. An example is the design of the blowdown system where older plants were designed in accordance with API 520 and 521 , which is prescriptive, whereas newer plants follow a more risk-based approach.

Opportunity for cost reduction: Keep to either NFPA 59A (prescriptive) or EN 1473 (risk based). Avoid a mix-and-match approach to select worst case in either, which adds to the cost. Use experience to challenge the interpretation of NFPA 59A to ensure that requirements are practical and fit for purpose and not at an excessive cost.

\section{Process Selection}

In 2017, 73 per cent of the world-scale liquefaction capacity used APCI processes, with the propane pre-cooled/mixed refrigerant $\mathrm{C} 3 / \mathrm{MR}^{23}$ being the most common at 43 per cent. The main alternative is the ConocoPhillips Optimized Cascade process $(\mathrm{CPOC})^{24}$ at 23 per cent. Figure 6 provides a breakdown.

\section{Figure 6: World-Scale Liquefaction Processes}

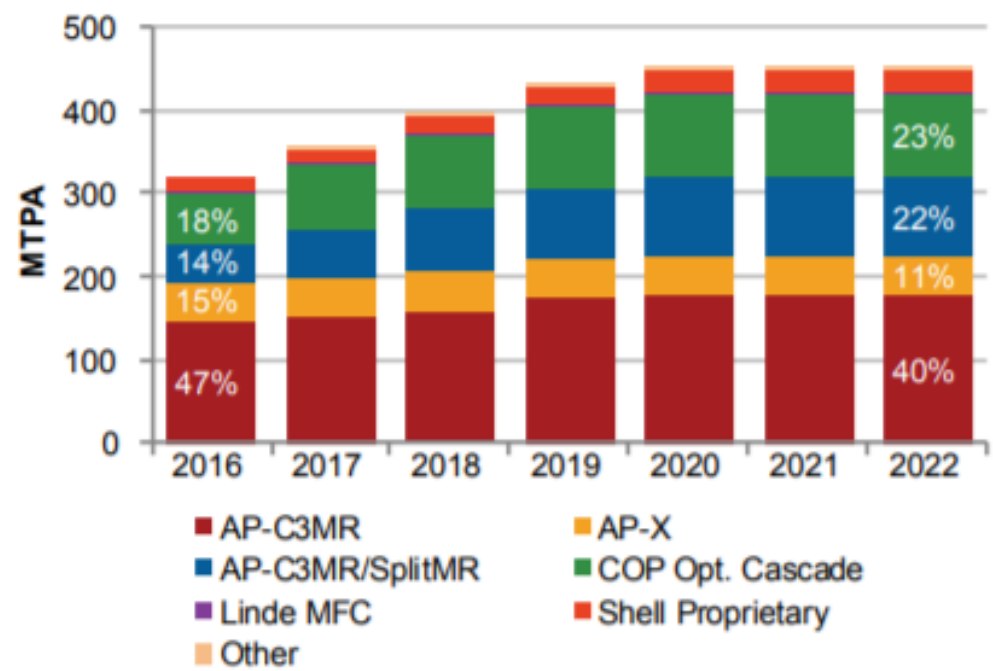

Source: IHS Markit/IGU 2017 World LNG Report ${ }^{25}$

The general view is that the cascade process offers a slightly lower capital cost but with a slightly higher operating cost due lower thermodynamic efficiency resulting in a higher fuel consumption. The

\footnotetext{
22 'Installation and equipment for liquefied natural gas. Design of onshore installations' "https://shop.bsigroup.com/ProductDetail/?pid=000000000030297214

23 'THE C3MR LIQUEFACTION CYCLE: VERSATILITY FOR A FAST GROWING, EVER CHANGING LNG INDUSTRY': http://www.ivt.ntnu.no/ept/fag/tep4215/innhold/LNG\%20Conferences/2007/fscommand/PS2 5 Pillarella s.pdf

${ }^{24}$ Base Load LNG By Cascade Refrigeration': https://ihsmarkit.com/products/chemical-technology-pep-reviews-base-load-Ingby-cascade-2003.html

25 'IGU 2017 World LNG Report': https://www.igu.org/sites/default/files/103419-World IGU Report no\%20crops.pdf
} 

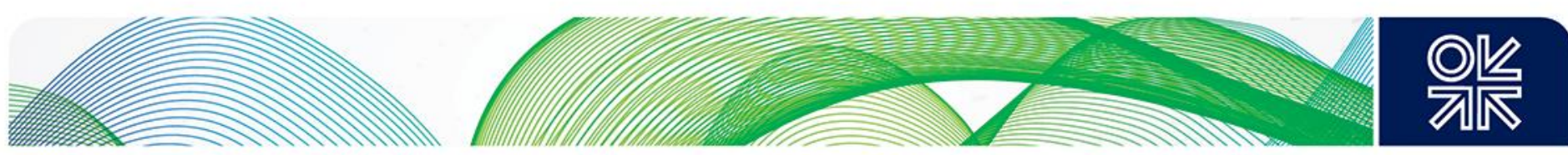

reverse being the situation for C3/MR - higher CAPEX but lower OPEX ${ }^{26}$. The C3MR process has traditionally dominated the market but there have been recent gains by the cascade process particularly in the USA and Australia where Bechtel was selected as the EPC contractor.

For mega LNG projects (Qatar Gas) APCI extended the capacity of the C3/MR process by adding a further nitrogen liquefaction step to increase the capacity to about $8 \mathrm{mtpa}$. This process referred to as AP-X enabled the use of larger frame 9 gas turbines. It will be interesting to see if this process is used again for the proposed expansion at Qatar and possibly in Mozambique, where ExxonMobil is considering large-scale plants to achieve an economy of scale.

The other world-scale processes include Shell DMR $^{27}$ (Sakhalin and Prelude) and Linde MFC ${ }^{28}$ (Snøhvit), but their use has been limited.

A process not included in figure 7 is Black and Veatch's PRICO ${ }^{29}$. This is based on a single mixed refrigerant and is suitable for plants up to $1.6 \mathrm{mtpa}$ so not normally considered for world-scale plants. However, it is being proposed for the Jordan Cove ${ }^{30}$ LNG project in Canada using $5 \times 1.56$ mtpa trains to produce $7.8 \mathrm{mtpa}$. This process is being used on the Golar FLNG projects and is regarded as robust and relatively easy to modularize.

The Elba Island LNG ${ }^{31}$ project being developed by Shell and Kinder Morgan will use the Shell MMLS $^{32}$ small-scale process comprising $10 \times 0.25 \mathrm{mtpa}$ trains to produce $2.5 \mathrm{mtpa}$. The process was developed primarily for the transport LNG market, but this project will export the LNG by ship to worldwide markets. The small units can be easily modularized and transported.

The more complex processes have more equipment resulting in a higher CAPEX but lower fuel consumption leading to a lower OPEX. Hence life-cycle costing methods must be considered, albeit CAPEX typically dominates at the final investment decision.

Opportunity for cost reduction: Study at technical definition stage to identify the lowest-cost option considering both CAPEX and OPEX. However, an established plant owner will understandably wish to continue using the same process due to familiarity and common spare equipment if an expansion at the same site. The use of a new process is more likely with a new player, for example PRICO for Pembina at Jordan Cove, Golar LNG with FLNG.

\section{Contract Execution Strategy}

Contracts were traditionally awarded on the basis competitive proposals for each stage of an LNG project, as shown in figure 7 .

\footnotetext{
26 'A COMPARATIVE STUDY OF PHILLIPS OPTIMIZED CASCADE AND APCI PROPANE PRE-COOLED MIXED REGRIGERANT LNG LIQUEFACTION PROCESSES': http://hydrocarbons21.com/files/lng-liquefaction-apci-propane-precooled-mixed-refrigerant-comparison-phillips-cascade.pdf

27 'Double mixed refrigerant LNG process provides viable alternative for tropical conditions': https://www.ogi.com/articles/print/volume-100/issue-27/processing/double-mixed-refrigerant-Ing-process-provides-viablealternative-for-tropical-conditions.html

28 'LNG Technology': https://www.linde-engineering.com/en/images/LNG 11 e 13 150dpi NB tcm19-4577.pdf

29 'SMALL SCALE PRICO LNG': https://www.bv.com/docs/energy-brochures/small-scale-prico.pdf

30 'Pembina says moving forward with US Jordan Cove LNG project': https://www.Ingworldnews.com/pembina-says-movingforward-with-us-jordan-cove-Ing-project/

'Elba Liquefaction Project \& EEC Modification Project':

https://www.kindermorgan.com/business/gas pipelines/projects/elbaLNG

32 'Small-scale LNG applications make progress': http://www.gasprocessingnews.com/features/201310/small-scale-Ingapplications-make-progress.aspx
} 

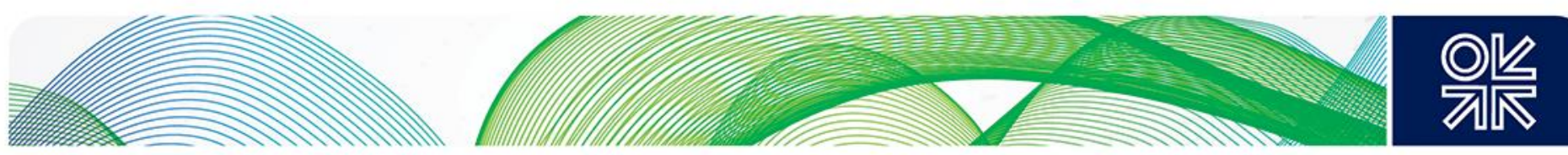

Figure 7: Project Stages

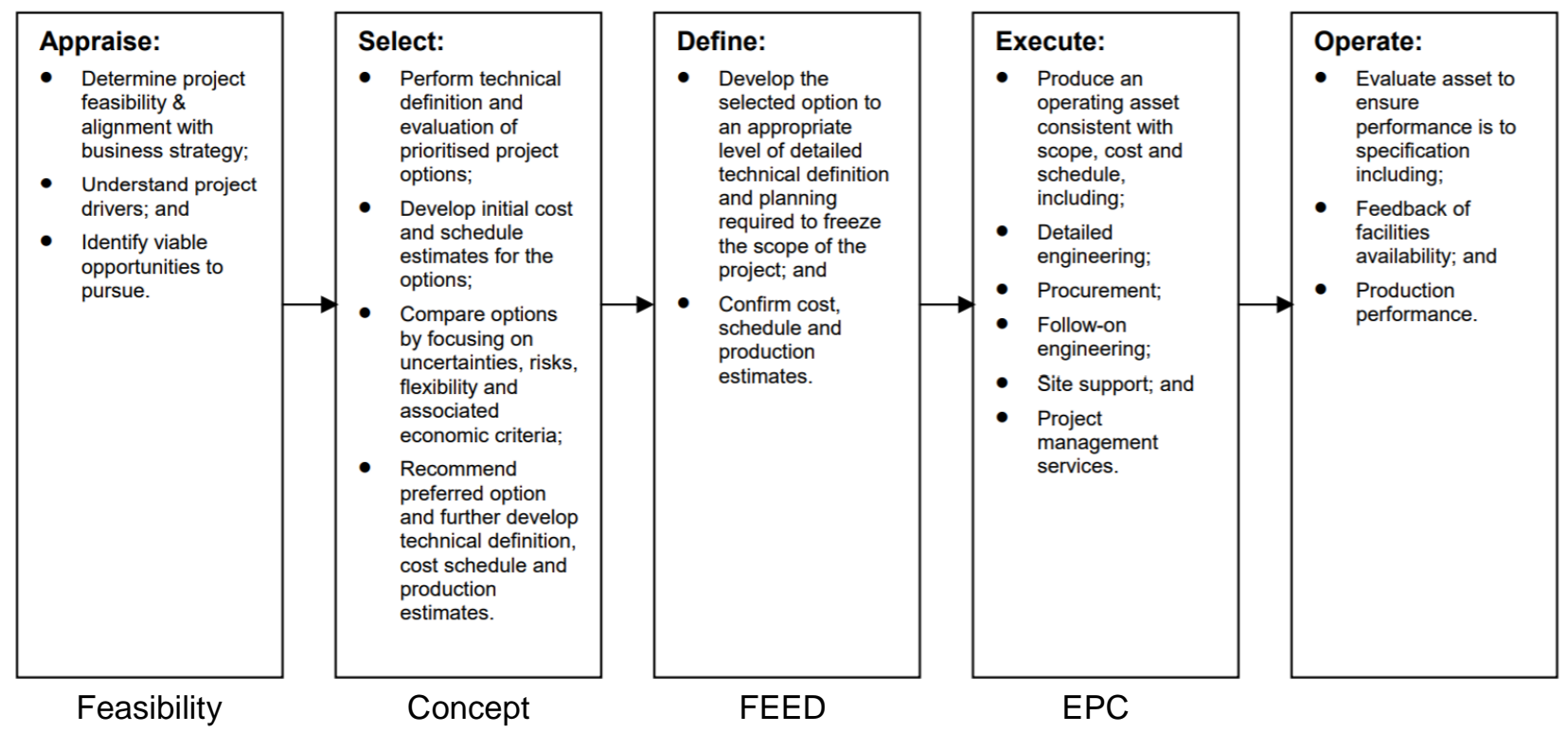

Source: Courtesy of BP

This process had significant drawbacks:

- It took considerably longer as each stage required inquiry documents to be prepared, issued, bid, evaluated and awarded with approvals at each stage.

- The FEED contractor was regarded as having a preferred position with the client for bidding the EPC stage. In fact, this was often the opposite as the contractor saw more risks and was often too expensive.

- The selected EPC contractor identified shortcomings in the FEED design or applied a "not invented here' approach leading to commercial issues.

This has led to new approaches, the main ones being:

- Select the contractor at the outset of the project based on experience and relationships (often referred to as a 'beauty parade'). Work with that contractor to develop the estimate and agree the lump-sum turn-key price and then deliver it. This approach appears to have worked well with Bechtel. This method can be contrary to the need for competitive bidding in certain countries.

- Award two or possibly three FEED contracts and include in the scope of work the preparation of the EPC contract price. This allows for a better understanding of the scope and avoids the 'not invented here' issue. However, it does raise concerns about the confidentiality of good cost-cutting ideas generated by the different contractors during the FEED stage.

The other decision is whether to award one EPC contract or break the work into major packages, such as process plant, tanks and jetty. The one-contract approach offers the lowest risk of cost increases as the management of the subcontracts rests with the main contractor. With the multipleaward approach many owners think they may be able to reduce the cost by managing the subcontractors directly and avoid paying the lead contractor that contingency and risk amount. The trend is to award a single lump-sum turn-key contract to a competent lead contractor and let that company manage the risk. This approach is favoured by the banks as the risk of cost overruns is seen as less. 

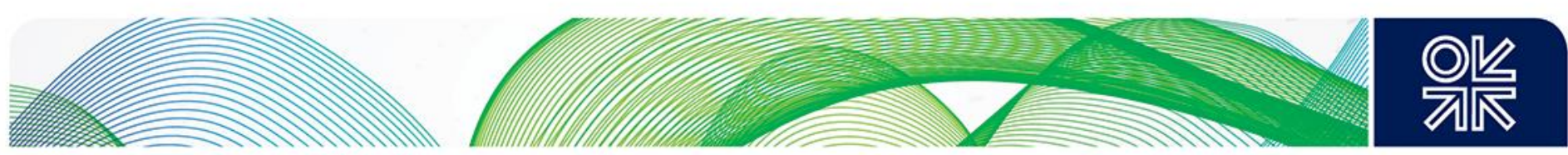

Another decision is whether to award the EPC contract on a lump-sum or reimbursable basis or a hybrid of cost plus a fee (contractor overhead and profit). The issue is the size of the contracts and whether the contractor can cover the risk. Large LNG projects can have a value in excess of the selected contractor's assets. This decision needs to be taken on a project-by-project basis depending on the contract value and the financial strength of the contractor(s). There is nothing to be gained by any of the parties if a contractor goes into liquidation - all parties lose. This is also true of joint ventures where there is normally joint and several liability.

Another aspect to be considered is the personnel resources of the owner. A simple lump-sum turnkey contract requires a much smaller client team as the contractor manages the interfaces. The reverse is true of projects broken into different contracts requiring a larger team to manage the overall project.

Local content also needs to be considered in the contract strategy. Many developing countries see major projects as an opportunity to employ and train local people. This is a challenge and must be managed by both the authorities in the country and the developer to ensure the right balance. This was the issue recently in Australia, where costs rose rapidly due to the limited number of in-country resources for so many projects and a restriction on bringing in foreign labour.

Opportunity for cost reduction: Minimize the schedule by selecting a single contractor from the outset to undertake the conceptual, FEED and EPC scopes and avoid the time taken for the bidding, selection and award of individual contracts. Select an EPC contract strategy that minimizes the risk to the developer, which will most likely be a single EPC contract on a lump-sum turn-key basis for the full scope of plant, tanks and jetties. Ensure that the selected contractor can take the full financial responsibility for delivering the project.

\section{Permitting and Environmental issues}

The main issues regarding permitting are normally environmental and relate to the impact during construction and then operation. The Corpus Christi Environmental Impact Statement ${ }^{33}$ is a good example of the scope of the information required for both the construction and operation phases.

\section{Construction}

This normally relates to the impact of the noise and traffic on the local community. Most liquefaction plants are built in remote or industrial areas and the issues are well understood and the process to manage them established. One major consideration is the carbon footprint and the need to minimize $\mathrm{CO}_{2}$ emissions during equipment manufacture and construction. Another major concern is dredging in shallow water locations and the impact on marine life. This requires extensive surveys and can be time consuming.

\section{Operation}

The main issues relate to $\mathrm{CO}_{2}$ emissions and marine impact.

\section{$\mathrm{CO}_{2}$ Emissions}

There are two sources of $\mathrm{CO}_{2}$. The first is that extracted from the feed gas to avoid freezing in the liquefaction process. The second is the exhaust from the gas turbines.

The feed gas $\mathrm{CO}_{2}$ could be compressed and reinjected into a reservoir (sequestration), a method is that is used at Gorgon and Snøhvit. Gorgon ${ }^{34}$ feed gas contains 13 to 14 per cent $\mathrm{CO}_{2}$ and the original concept required a $7 \mathrm{~km}$ onshore pipeline to inject 3.3 mtpa of extracted $\mathrm{CO}_{2}$ into existing oil wells at an overall cost of $\$ 2.0 \mathrm{bn}$. Based on $15 \mathrm{mtpa} L \mathrm{LNG}$ production this would add $\$ 130 / \mathrm{mtpa}$ to the

\footnotetext{
33 'Corpus Christi Environmental Impact Statement': https://www.energy.gov/sites/prod/files/2014/10/f18/EIS-0493-FEIS2014.pdf

34 'Gorgon Fact Sheet: Carbon Dioxide Capture and Storage Project': https://sequestration.mit.edu/tools/projects/gorgon.html
} 

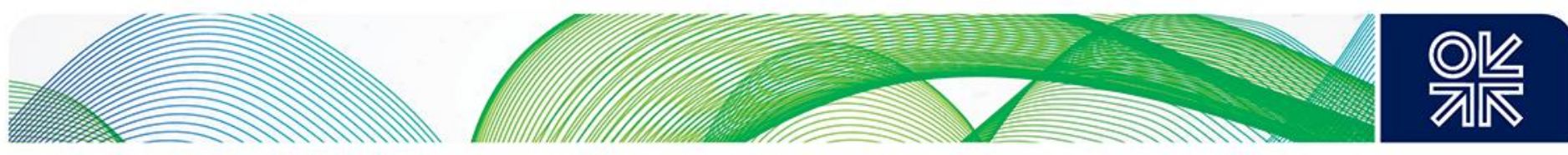

project cost. The revised scheme uses new injection wells located onshore. Snøhvit 35 feed gas contains 5 to 8 per cent $\mathrm{CO}_{2}$ and $0.7 \mathrm{mtpa}$ of extracted $\mathrm{CO}_{2}$ are transported via a $153 \mathrm{~km}$ offshore pipeline to an offshore sandstone reservoir at a cost of $\$ 250$ million. Based on 4.1 mtpa production this adds $\$ 60 /$ tpa to the project cost.

The recovery of $\mathrm{CO}_{2}$ from gas turbine exhaust gases is not regarded as economic. The best approach to reduce $\mathrm{CO}_{2}$ emissions is to use high efficiency aero-derivative gas turbines which offer lower emissions. Combined cycle units recovering heat via steam turbines also improve the efficiency and lower the $\mathrm{CO}_{2}$ emissions but are expensive and the extra cost is often difficult to justify. In cases where there is a high $\mathrm{CO}_{2}$ content in the feed gas, the waste heat is used to regenerate the amine solution either by using steam or a heat transfer fluid. This has to be evaluated on a field-specific basis. As extreme examples, Gorgon feed gas contains 13 to 14 per cent $\mathrm{CO}_{2}{ }^{36}$, whereas Sabine Pass (pipeline gas) just 0.3 per cent, requiring very different waste heat demands.

An alternative approach would be to use electric drives instead of gas turbines. This was used at the Snøhvit plant ${ }^{37}$, but the power was generated by gas turbines at site backed up by power from the grid. For this solution to bring a significant reduction in $\mathrm{CO}_{2}$ emissions the power would need to be generated from renewable sources, such as wind or solar or nuclear. An all-electric LNG option is also being used for Freeport e-LNG ${ }^{38}$ which is scheduled to commence operations in 2019.

A study by $\mathrm{ABB}^{39}$ using onsite power generation states that the CAPEX is higher but the OPEX is reduced and the payback is just a few months. One main factor contributing to the rapid payback is the increase in availability of motors compared with gas turbines, providing 10 additional days of production per year. Studies by Siemens $/$ Shell $\left.\right|^{40}$ and Bechtel ${ }^{41}$ state that the concept is feasible, but they were more guarded about the economic advantages.

As stated earlier, most projects evaluate life-cycle economics, but frequently the lowest capital cost is key to the final investment decision or, in more everyday jargon, 'cash is king'.

\section{Marine Impact and Dredging}

LNG tankers require deep water access and typically a $12 \mathrm{~m}$ draft. The first approach to achieve this is to use a jetty which, in some cases, can be very long and expensive. An example is the recently constructed $2.1 \mathrm{~km}$ jetty at Gorgon at a cost of $\$ 1.4 \mathrm{bn}{ }^{42}$.

Unless there is a natural deep-water harbour, dredging is required to provide an access channel and a turning basin. In remote locations a harbour and temporary jetty is also required for offloading equipment and mooring tugs and possibly offshore facility support vessels. Dredging is not just a construction activity but an ongoing maintenance activity to maintain the depth of the channel, and is both expensive and environmentally challenging given its impact on marine life and the local fishing industry.

\footnotetext{
35 'Snøhvit LNG Project: Status and progress of the project execution':

http://www.ivt.ntnu.no/ept/fag/tep4215/innhold/LNG\%20Conferences/2005/SDS TIF/050123PR.pdf

36 'Factbox: Projected CO2 emissions from top Australia LNG projects': https://www.reuters.com/article/us-australia-Ing-carbonfb-idUSTRE7491FU20110510

37 'Pushing the limits of productivity: The all-electric liquefaction plant concept'

https://www.energy.siemens.com/nl/pool/hq/industries-utilities/oil-

gas/applications/lng/Pushing\%20the\%20limits\%20of\%20productivity EN.pdf

38 'eLNG Means Electric and Eco-friendly': http://freeportlng.com/our-business/elng

39 'All electric LNG plants: Better, safer, more reliable - and profitable':

https://library.e.abb.com/public/9e770a172afc8d7ec125779e004b9974/Paper\%20LNG Rev\%20A lowres.pdf

40 'All Electric Driven Refrigeration Compressors in LNG Plants Offer Advantages'

http://www.ivt.ntnu.no/ept/fag/tep4215/innhold/LNG\%20Conferences/2005/SDS TIF/050161.pdf

${ }^{41}$ 'All Electric Motor Drives for LNG Plants':

http://static.conocophillips.com/files/resources/smid 016 gastechelectricmotorpaper.pdf

42 'Gorgon LNG Jetty and Marine Structures Project': https://www.cimic.com.au/our-business/projects/completedprojects/gorgon-Ing-jetty-and-marine-structures-project
} 

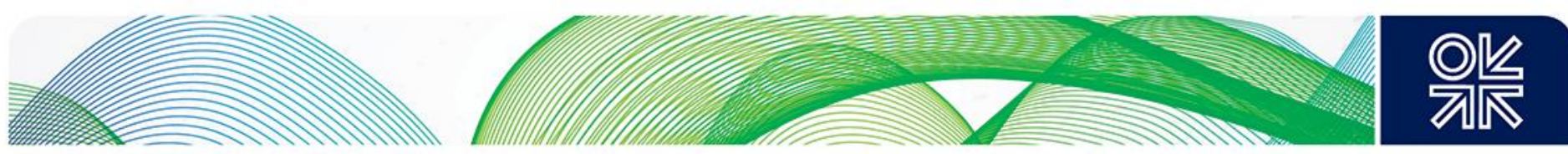

The option exists to use a subsea LNG transfer line instead of a conventional jetty and load the ship via an offshore structure. The technology is available for distances of up to 10 miles $(18 \mathrm{~km})^{43}$. Subsea transfer lines have been used for LPG transfer and offloading at $-52^{\circ} \mathrm{C}^{44}$ on the Camisea project in Peru. Pipe-in-pipe technologies are available from several companies, including Fluor ${ }^{45}$ and InTerPipe (ITP) ${ }^{46}$. No commercial LNG applications have been identified, although many studies have been undertaken. OTC paper $18542^{47}$ 'Update on Subsea LNG Pipeline Technology' is helpful in understanding the technology and the costs.

Opportunity for cost reduction: Try to select a site with a deep-water access to minimize dredging which is expensive, not only as a capital cost but also as an operating cost. Dredging also raises environmental issues with the impact on marine life and fishing. Monitor the progress of subsea LNG pipeline technology.

\footnotetext{
43 'Buried, subsea line advanced as LNG alternative': https://www.ogj.com/articles/print/volume-103/issue-42/specialreport/buried-subsea-line-advanced-as-Ing-alternative.html

${ }^{44}$ Highly Insulated Pipeline Systems: Projects: $\underline{\text { https: //www.itp-interpipe.com/projects }}$

45 'Subsea LNG Cryogenic Pipeline': https://www.fluor.com/about-fluor/corporate-information/technologies/fluor-subsea-Ingcryogenic-pipelines

${ }^{46}$ Highly Insulated Pipeline Systems: https://www.itp-interpipe.com/

47 'Update on Subsea LNG Pipeline Technology':

https://www.researchgate.net/publication/254519335 Update on Subsea LNG Pipeline Technology
} 

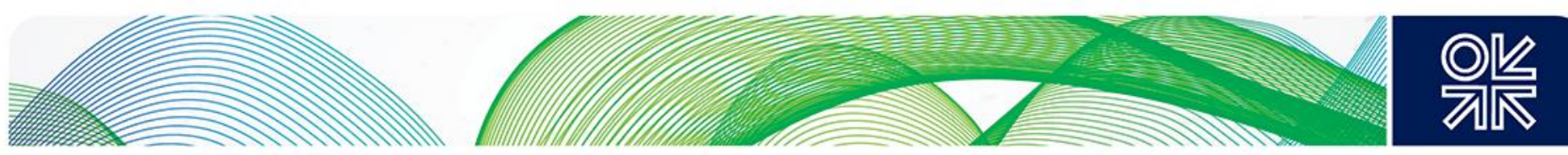

\section{Chapter 6. Operating Costs and Opportunities for Cost Reduction}

Operating costs include:

- fuel gas consumption

- operations personnel

- maintenance

- consumables

- $\quad$ support vessel costs, such as tugs

- insurance.

\section{Fuel Gas Consumption}

This is typically the largest single operating cost, using approximately 10 to 12 per cent of the feed gas depending on the liquefaction process used. Some processes quote figures as low as 8 per cent, but care needs to be taken as to whether this includes the fuel gas for electrical power generation. Most plants generate the power on site to ensure high availability. Fuel gas consumption is often referred to as 'shrinkage', being the difference between the feed gas entering the plant and LNG produced. The main user will be the refrigerant compressor drivers, in other words gas turbines or steam boilers for steam turbine drivers. A figure of 9.5 per cent has been quoted for Sabine Pass ${ }^{48}$.

The cost of gas is accounted for very differently by different energy companies. Some regard it as a zero-cost item as it is owned by them and, if not used now, would be produced in 20 years at a very low discounted value. Others regard it as a lost opportunity cost and will charge it at the LNG delivery price. This paper assumes a cost of $\$ 5 / \mathrm{mmbtu}$, but this could be higher for deep-water offshore production.

For a typical two-train $\times 4.5$ mtpa rich gas plant, such as Wheatstone ${ }^{49}$, the refrigeration power needs are typically $516 \mathrm{MW}$ of installed power (12 x $43 \mathrm{MW}$ gas turbines). Electrical power needs would be typically $172 \mathrm{MW}$ (4 x $43 \mathrm{MW}$ gas turbines) giving a total of $688 \mathrm{MW}$ of installed power.

Assuming an open cycle efficiency of 41 per cent gives a total consumption of $1678 \mathrm{MW}$, and using $\$ 5 / \mathrm{mmbtu}$ the cost would be in the order of $\$ 200-250$ million per year. For a simpler two-train $\times 4.5$ lean gas plant similar to Sabine Pass the cost would be less, at \$150-170 million per year.

Open cycle gas turbines are normally used on LNG plants as the use of higher-efficiency combined cycle units adds the need for costly water treatment plant and related systems. As well as adding cost, they are outside the normal operational experience of upstream oil and gas companies that prefer simpler and more robust plants, particularly for remote locations. Steam systems are more common in refinery and petrochemical plants and require specific skill sets.

Figure 8 compares the fuel consumption of the Sabine Pass, Queensland Curtis, Wheatstone and Gorgon expressed as $\$ / \mathrm{mmbtu}$. It shows the higher power consumption for the more complex rich gas Wheatstone and Gorgon plants. The slightly higher figure for Gorgon over Wheatstone probably reflects the additional energy needs for $\mathrm{CO}_{2}$ sequestration.

\footnotetext{
48 'What is the real cost of processing in an LNG plant?': https://www.quora.com/What-is-the-real-cost-of-processing-in-an-LNGplant

49 'Environmental Impact Statement/Environmental Review and Management Programme for the Proposed Gorgon Development': http://www.epa.wa.gov.au/sites/default/files/PER documentation/1496-ERMP-EISMain\%20Report\%20Volume\%20II-HR.pdf
} 

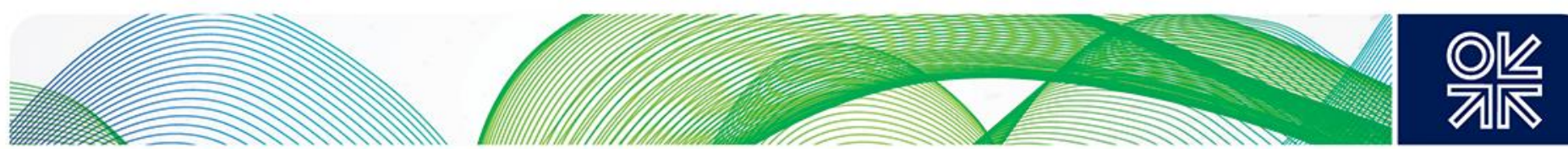

Figure 8: Fuel Gas Cost $\$ / \mathrm{mmbtu}$

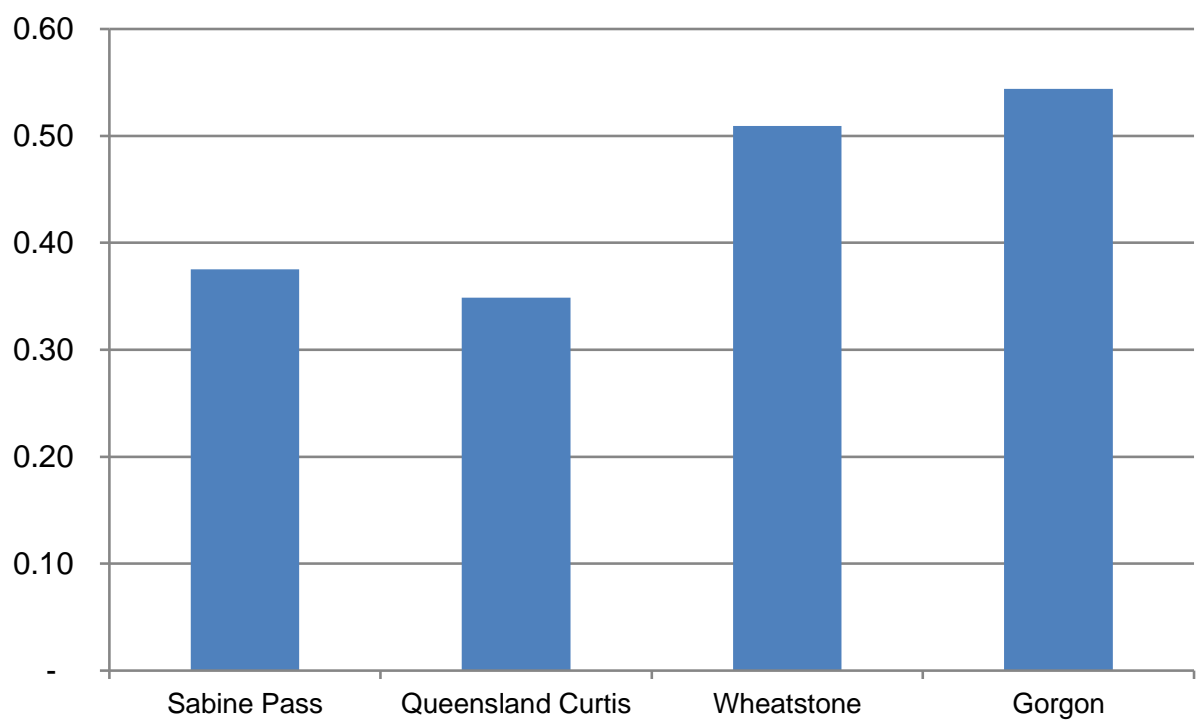

Source: By author based on analysis of published data

Opportunity for cost reduction: Further improvements in the thermodynamic efficiency of the liquefaction processes, but these have been optimized and any improvement would likely require additional plant and equipment, increasing the CAPEX. Life-cycle costing studies optimize this but simple plant with a lower CAPEX usually wins the day. An example of this would be improving the heat recovery by using combined cycle systems on the gas turbines, but this requires steam plant and water treatment plant, adding significant capital cost and operational complexity. However, this could be a practical consideration if the LNG plant was located in a petrochemical or refinery complex. It should be noted that waste heat is recovered from the exhaust gases for process use, which often balances the need for amine regeneration in the $\mathrm{CO}_{2}$ absorption plant, and many plants use a heat transfer fluid rather than introducing steam systems.

\section{Operations Personnel}

The number of personnel required depends on the size and complexity of the plant. On a large and highly complex facility like Gorgon, which in addition to liquefaction includes $\mathrm{CO}_{2}$ compression and sequestration, condensate production and operation of the upstream subsea facilities, this would be around $300-350$ on a regular basis ${ }^{50}$ for producing $15 \mathrm{mtpa}$ (three trains). Whereas for a simpler plant like Sabine Pass using treated pipeline gas this would be less, typically at 240 for $18 \mathrm{mtpa}$ (six trains).

Figure 9 compares the numbers of personnel per unit of production (mtpa). Comparing Gorgon (three trains, $15 \mathrm{mtpa}$ ) and Wheatstone (two trains, $8.5 \mathrm{mtpa}$ ) shows the economy of scale of the larger plant. Comparing the Gorgon/Wheatstone and Queensland Curtis/Sabine Pass personnel count shows the smaller numbers needed to operate a simple lean gas plant with no LPG and condensate production.

\footnotetext{
50 'Environmental Impact Statement/Environmental Review and Management Programme for the Proposed Gorgon Development': http://www.epa.wa.gov.au/sites/default/files/PER documentation/1496-ERMP-EISMain\%20Report\%20Volume\%20II-HR.pdf
} 

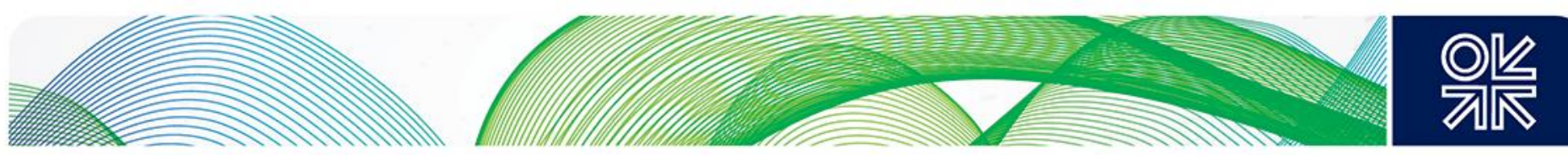

Figure 9: Personnel Count/mtpa

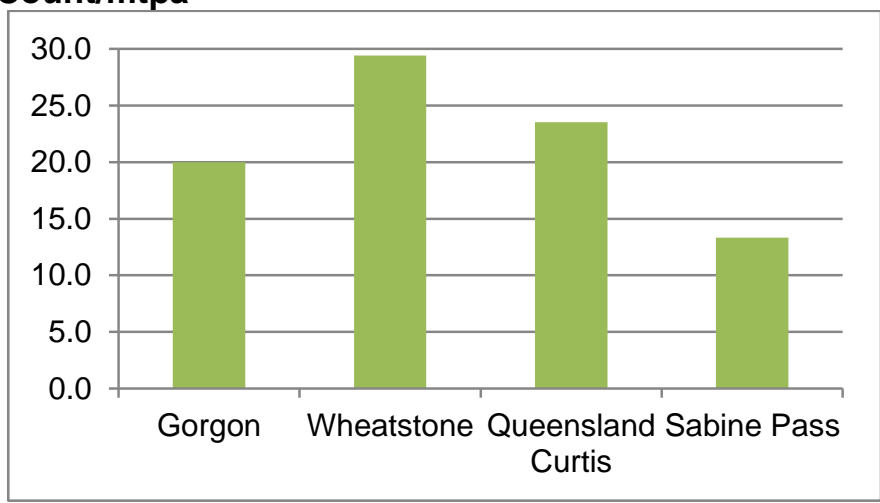

Source: By author based on analysis of published data

In terms of cost these personnel numbers represent $\$ 60$ million per year for Gorgon, $\$ 50$ for Wheatstone and $\$ 34$ for Queensland Curtis, assuming $\$ 200,000 /$ year per person for a remote location where people have to be transported and housed. For Sabine Pass the cost is lower at $\$ 26$ million/year, assuming $\$ 130,000 /$ year ${ }^{51}$ per person as the plant is located in an established industrial area. These costs expressed as $\$ / \mathrm{mtpa}$ are compared in figure 10. Comparing Gorgon and Wheatstone demonstrates the economy of scale of a larger capacity plant.

Figure 10: Personnel Cost $\$ \mathrm{~m} / \mathrm{mtpa}$

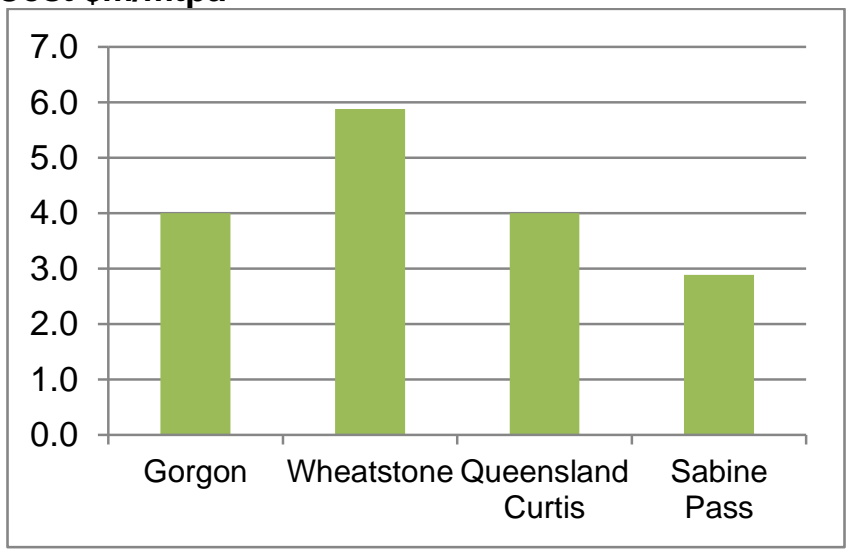

Source: By author based on analysis of published data

Opportunity for cost reduction: The economy of scale is likely to be the largest driver to reduce plant manning cost per ton. This leads to the use of more identical trains which can be operated with fewer people on a pro-rata basis. This is the case with Sabine Pass with six identical trains. The other approach to achieve an economy of scale is to use larger capacity plants. Large-scale 7.6 mtpa trains are being considered for Mozambique, compared with the original 5 mtpa. This would not only reduce personnel costs but LNG delivery costs as quoted by Exxon: 'The larger train design will lower the unit cost of the Rovuma LNG project and ensure a competitive new supply for the global LNG market'52.

\footnotetext{
51 'Environmental Assessment for the Sabine Pass Liquefaction Project': https://www.energy.gov/sites/prod/files/EA-1845-FEA2011.pdf

52 'Exxon beefs up Mozambique LNG project to cut costs ahead of bank talks': https://www.reuters.com/article/us-exxonmozambique-Ing/exxon-beefs-up-mozambique-Ing-project-to-cut-costs-ahead-of-bank-talks-idUSKBN1K22PG\#
} 

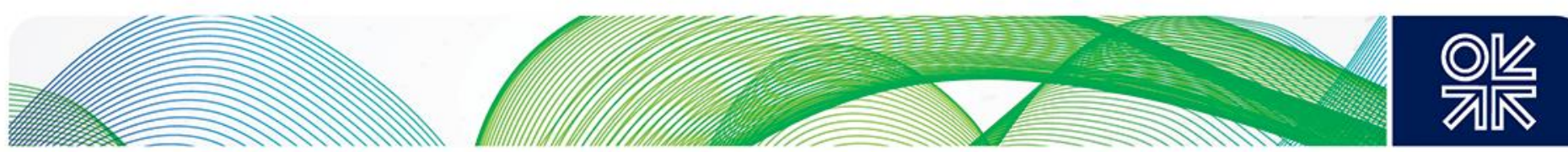

\section{Consumables}

This covers the make-up of refrigerants losses, fresh water for amine units, lubricating oil, diesel oil, chemicals and similar items. For some processes the refrigerants may be extracted from the feed gas, but this will depend on the composition, in other words, extraction of propane and butane.

\section{Maintenance and Spares}

This includes the ongoing maintenance plus the major plant overhauls expected every 3-4 years, which will require additional personnel. For maintenance only at an estimated CAPEX of $\$ 22$ billion, this would be $\$ 10-20$ million/year, and Queensland Curtis at $\$ 12$ billion CAPEX would be $\$ 4-8$ million per year.

Opportunity for cost reduction: More competition between suppliers and more condition-based maintenance.

\section{Tug and Support Vessels}

A minimum of two and possibly three tugs will be required to manoeuvre the shuttle tanker alongside the jetty for offloading. These tugs would probably be dedicated to the project as it may not be practical to return to port between offloading, depending on the offloading frequency. An 8.5 mtpa plant offloading to a $140,000 \mathrm{~m}^{3}$ tankers will require approximately 130 ships/year (11 per month). Using larger $173,000 \mathrm{~m}^{3}$ ships reduces this to 106 ships per year (9 per month).

\section{Insurance}

Onshore liquefaction plant insurance is in the range of 0.03 to 0.07 per cent ${ }^{53}$ of the site value. For the Gorgon liquefaction plant only at an estimated cost of $\$ 22$ billion this would be $\$ 10-20$ million/year and Queensland Curtis at $\$ 12$ billion would be $\$ 4-8$ million per year.

\section{Summary and Analysis}

Table 6 summarizes operating costs discussed in this chapter based on the best estimates by the authors from published data. Specific data is regarded as commercially sensitive and confidential by the operators.

\footnotetext{
53 'Floating Liquefaction (FLNG): Potential for Wider Deployment': https://www.oxfordenergy.org/wpcms/wpcontent/uploads/2016/11/Floating-Liquefaction-FLNG-NG-107.pdf
} 

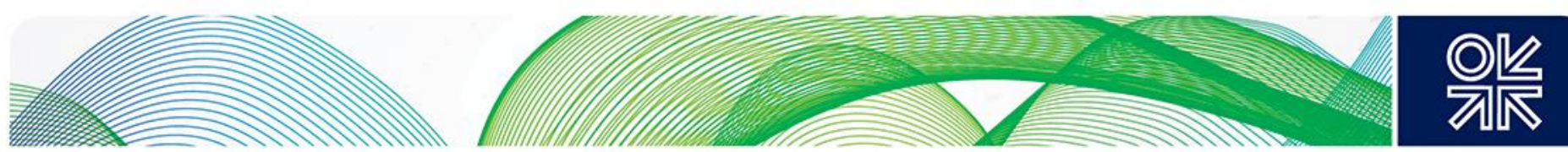

Table 6: OPEX Cost Summaries

\begin{tabular}{|l|c|c|c|c|}
\hline & Gorgon & Wheatstone & $\begin{array}{c}\text { Queensland } \\
\text { Curtis }\end{array}$ & Sabine Pass \\
\hline OPEX component & \multicolumn{4}{|c|}{ \$million/year } \\
\hline Fuel gas at \$5/mmbtu & 385 & 227 & 148 & 338 \\
\hline Personnel & 66 & 50 & 30 & 32 \\
\hline Maintenance and Spares & 469 & 256 & 170 & 141 \\
\hline Consumables & 40 & 50 & 25 & 50 \\
\hline Tugs & 20 & 20 & 20 & 20 \\
\hline Insurance & 17 & 9 & 6 & 5 \\
\hline OPEX including fuel & 996 & 611 & 399 & 586 \\
\hline OPEX \$/tpa & 66 & 72 & 47 & 33 \\
\hline OPEX \$/mmbtu & 1.33 & 1.44 & 0.94 & 0.65 \\
\hline OPEX less fuel & 611 & $\mathbf{3 8 5}$ & $\mathbf{2 5 1}$ & $\mathbf{2 4 8}$ \\
\hline OPEX less fuel \% CAPEX & $1.9 \%$ & $2.1 \%$ & $2.1 \%$ & $2.5 \%$ \\
\hline OPEX less fuel \$/mmbtu & 0.81 & 0.90 & 0.59 & 0.28 \\
\hline \% Feed gas cost & $27 \%$ & $29 \%$ & $19 \%$ & $13 \%$ \\
\hline
\end{tabular}

Source: By author based on analysis of published data

Some observations from the review of the table:

- The figure for OPEX less fuel as percentage of CAPEX aligns well with the industry norm of 2.5 per cent54.

- The OPEX as percentage of feed gas cost for Sabine Pass at 13 per cent aligns well with Cheniere contract of 115 per cent HH55, in other words, 100 per cent of Henry Hub is the cost of the gas to be liquefied, plus 15 per cent for the OPEX costs. The plant CAPEX is covered by the fixed fee of $\$ 2.25-3.00 / \mathrm{mmbtu}$.

- The higher OPEX figures for Gorgon and Wheatstone reflect the more complex plant and remote locations. However as percentage of CAPEX they are lower, as the CAPEX is relatively high.

Figure 11 shows the distribution of the OPEX components for Sabine Pass based on the analysis of the published data.

\footnotetext{
54 'SME OPPORTUNITY GUIDE FOR AUSTRALIAN LNG OPERATIONS AND MAINTENANCE CONTRACTING ACTIVITIES': https://icn.org.au/sites/default/files/SME\%20Opportunity\%20Guide\%20for\%20Australian\%20LNG\%200perations\%20and\%20 Maintenance\%20Contracting\%20Activities.pdf

55 'Overview of Cheniere's sale and purchase contracts': https://marketrealist.com/2014/10/overview-chenieres-sale-purchasecontracts
} 


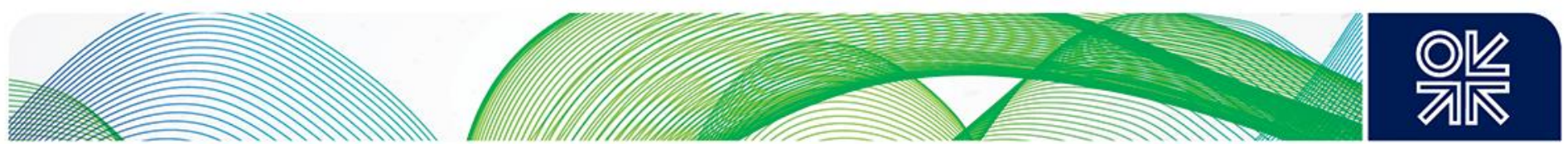

Figure 11: Typical OPEX Breakdown

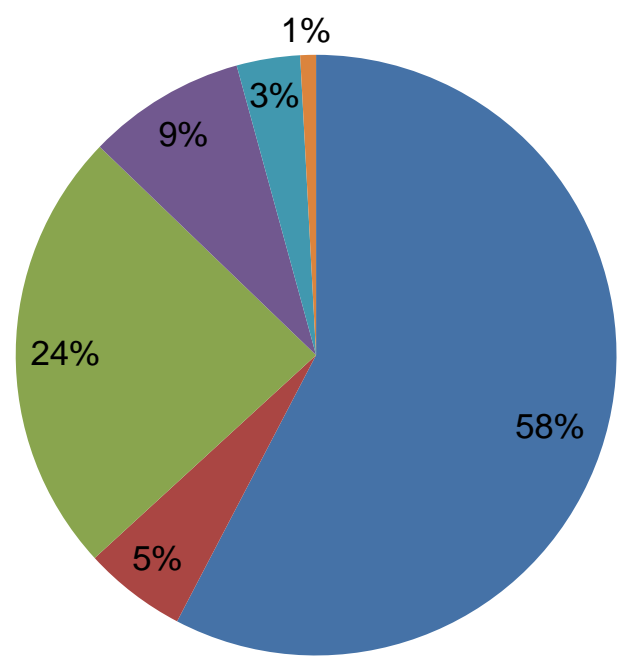

- Fuel Gas at $\$ 5 / \mathrm{mmbtu}$

- Personnel

Maintenance \& Spares

- Consumables

- Tugs

- Insurance

Source: By author based on analysis of published data 

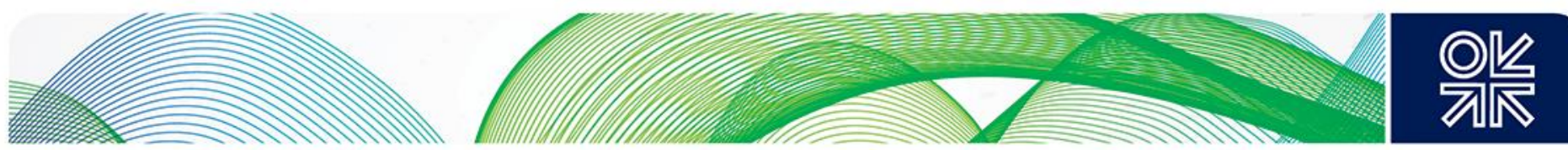

\section{Chapter 7. Production Costs}

Production costs shown in table 7 have been calculated by adding the unit capital costs shown in table 5 and the operating costs in table 6.

The intention of this table is to help developers estimate production costs for different plant complexities, such as lean gas or rich gas and different plant locations.

Table 7: Production Costs $\$ / \mathrm{mmbtu}$

\begin{tabular}{|c|c|c|c|c|}
\hline \multirow{2}{*}{ Location } & \multicolumn{2}{|c|}{ Brownfield (Expansion) } & \multicolumn{2}{|c|}{ Greenfield } \\
\hline & Lean Gas & Rich Gas & Lean Gas & Rich Gas \\
\hline Australia & 4.4 & 6.0 & 6.4 & 8.4 \\
\hline Remote & 4.0 & 5.2 & 5.6 & 6.6 \\
\hline USA & 3.1 & $\mathrm{~N} / \mathrm{A}$ - shale gas & 4.3 & $\mathrm{~N} / \mathrm{A}$ - shale gas \\
\hline FLNG Bespoke & \multirow{2}{*}{\multicolumn{2}{|c|}{$\begin{array}{l}\text { N/A - not realistic to expand FLNG. } \\
\text { Replace with larger unit or add second } \\
\text { unit. }\end{array}$}} & 4.3 & 8.3 \\
\hline FLNG Functional & & & 3.2 & $\begin{array}{c}\mathrm{N} / \mathrm{A} \text { - rich gas will } \\
\text { be bespoke }\end{array}$ \\
\hline
\end{tabular}

Source: By author based on analysis of published data

\section{Estimating the Costs of Upcoming Projects}

It is anticipated that the next phase of liquefaction plants with be in Mozambique and Qatar.

Referring to table 7, Mozambique is probably best aligned to a remote location and rich gas processing, which would indicate a unit cost of $\$ 6-7 / \mathrm{mmbtu}$.

Qatar will likely be a brownfield project located on the existing site where there is efficient and costeffective labour and is more aligned to the USA for construction costs. The gas will be lean as the liquids are removed upstream, so a unit cost of $\$ 3-4 / \mathrm{mmbtu}$ would look reasonable assuming no additional tanks or jetties. If these were added then $\$ 4-5 / \mathrm{mmbtu}$ would appear more realistic.

Please note that these costs are based on the projects researched for this paper and do not factor in any possible future changes in the project execution market, such as further recovery in the oil price reducing competitiveness in the contractor and equipment supplier market. It should also be noted that the very high costs experienced in Australia were due to the many projects being executed at the same time - this may not be the same if a single project was executed, albeit Australian labour costs are still relatively expensive compared with the rest of the world ${ }^{56}$.

\footnotetext{
56 'Australian cities in top 25 most expensive to build in worldwide': 

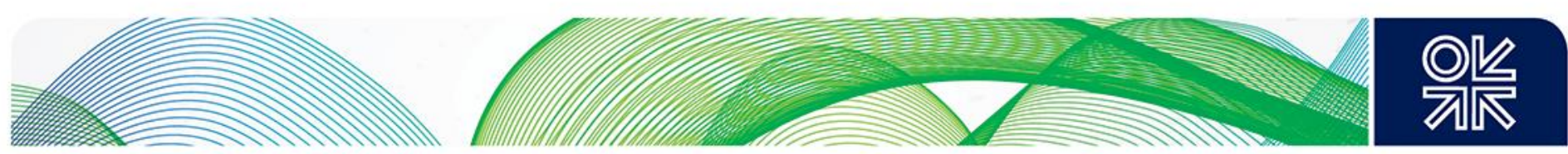

\section{Chapter 8. Conclusions}

\section{Reasons for Cost Reduction}

Liquefaction plant costs have dropped significantly in the past four years since the highs experienced with the Australian plants. This is mainly due to:

- Lower construction costs at the other locations. Construction is the largest single cost component and can represent 30 to 50 per cent of the final plant cost.

- A reduction in the cost of process plants globally due to increasing competition between contractors and equipment suppliers following the downturn in the oil and gas industry due the fall in oil prices

- A move away from bespoke company standards and specifications to the use of functional industry standards, and from 'preference design' to a more 'fit for purpose' approach.

- The introduction of new enabling technologies, such as floating liquefaction plants for offshore gas fields.

- The building of repeat identical trains to capture the economy of scale, for example Sabine pass will have six identical trains.

- In the case of the USA, building plants on existing import terminal sites utilizing the existing infrastructure and processing lean pipeline gas.

\section{Take Care with Unit Costs}

Many developers use the 'unit cost' figure for initial cost estimating, but great care must be taken to take into account plant complexity and the location factors. Care must also be taken as to whether the unit cost includes the upstream facilities of delivering the gas to the liquefaction plant. Many plant costs quoted in the literature are the project costs and include the upstream facilities. In the case of a complex deep-water development this can equal the cost of the liquefaction and double the unit cost figure.

\section{Contract Execution Strategy}

The industry has traditionally delivered new projects by breaking the execution into discrete stages: feasibility, conceptual design, FEED and EPC, often using different specialist contractors for each. While this allows good control it adds considerable time, as each as each stage must be bid for, evaluated and awarded prior to execution. It also breaks the continuity of the design teams and introduces a 'not invented here' approach at the next stage, leading to design changes which add costs and extend the schedule.

Some developers have overcome some of these issues by combing the FEED and EPC scopes in the form of a design competition, where the EPC price is generated during the FEED and awarded to the successful contractor. This can reduce the project schedule by 6-12 months.

However, the most efficient approach is to select a contractor from the outset and work with them to deliver the project. Ideally this is on a lump-sum turn-key basis, minimizing cost overruns for the owner and the lenders.

\section{Opportunities for Further Cost Reduction}

For many developers the approach by Cheniere and the other USA shale gas liquefaction plants sets a pattern for lower-cost developments. In summary: build the plant in an existing industrial area with cost-effective labour and use existing infrastructure wherever possible. Of course, this is not always possible and the following should be considered: 

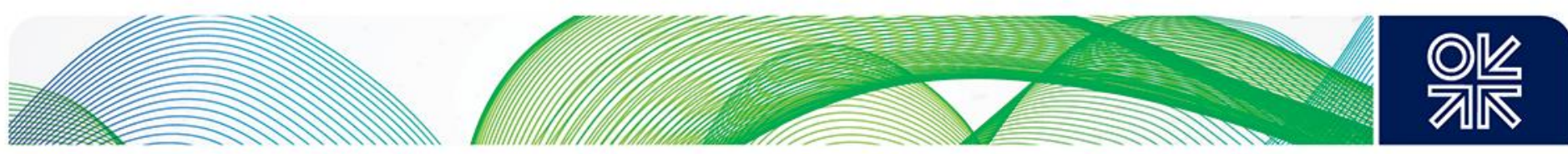

- Use floating liquefaction for remote deep-water offshore gas fields to eliminate the cost of expensive subsea pipelines.

- Use repeat designs to get an economy of scale - design one build many, as at Sabine Pass.

- Use larger trains to get an economy of scale, for example Exxon in Mozambique is considering $7.6 \mathrm{mtpa}$ trains similar to Qatar.

- Use industry standard functional specifications rather than bespoke company standards.

- Consider other liquefaction processes, for example PRICO for Jordan Cove.

\section{Operating Costs}

Fuel consumption is normally the largest operating cost, assuming the gas feed is charged at a commercial rate. Fuel consumption can be reduced by using more efficient equipment, such as combine cycle power plants, but this adds more plant and cost, and life-cycle costing needs to be used to justify this approach. Normally the lowest capital cost approach wins for FID.

\section{Future Project Costs}

Table 7 suggests liquefaction plant production costs (CAPEX + OPEX) which may assist developers in preparing preliminary cost estimates of future projects. These costs are for the liquefaction scope only and exclude the cost of the upstream facilities. Please note that these costs are based on the projects researched for this paper and do not factor in any possible future changes in the project execution market, such as further recovery in the oil price reducing competitiveness in the contractor and equipment supplier market. 
Appendix 1. Project Costs and References

\begin{tabular}{|c|c|c|c|c|c|c|c|c|c|c|}
\hline \multirow[b]{2}{*}{ Project } & \multirow[b]{2}{*}{ Location } & \multirow[b]{2}{*}{ mtpa } & \multirow[b]{2}{*}{ Trains } & \multicolumn{3}{|c|}{ Project } & \multicolumn{4}{|c|}{ Liquefaction Plant } \\
\hline & & & & $\begin{array}{c}\text { CAPEX } \\
\$ \text { \$bn }\end{array}$ & $\$ / t p a$ & $\$ / m m b t u$ & $\begin{array}{c}\% \text { project } \\
\text { CAPEX }\end{array}$ & $\begin{array}{c}\text { CAPEX } \\
\$ \text { \$bn }\end{array}$ & $\$ / t p a$ & $\$ / m m b t u$ \\
\hline Gorgon & Australia & 15.6 & 3 & 53.0 & 3,397 & 11.9 & $62 \%$ & 32.9 & 2,106 & 7.37 \\
\hline Prelude FLNG & Timor Sea & 3.6 & 1 & 12.0 & 3,333 & 11.7 & $60 \%$ & 7.2 & 2,000 & 7.00 \\
\hline Wheatstone & Australia & 8.9 & 2 & 34.0 & 3,820 & 13.4 & $52 \%$ & 17.7 & 1,987 & 6.95 \\
\hline Ichthys & Australia & 8.4 & 2 & 36.0 & 4,286 & 15.0 & $45 \%$ & 16.2 & 1,929 & 6.75 \\
\hline Queenland Curtis & Australia & 8.5 & 2 & 20.0 & 2,353 & 8.2 & $60 \%$ & 12.0 & 1,412 & 4.94 \\
\hline PNG & PNG & 6.9 & 2 & 19.0 & 2,754 & 9.6 & $49 \%$ & 9.3 & 1,349 & 4.72 \\
\hline Yamal & Russia & 16.6 & 3 & 27.2 & 1,639 & 5.7 & $80 \%$ & 21.8 & 1,311 & 4.59 \\
\hline Angola LNG & Angola & 5.2 & 1 & 10.0 & 1,923 & 6.7 & $60 \%$ & 6.0 & 1,154 & 4.04 \\
\hline Donggi-Senoro & Indonesia & 2.0 & 1 & 2.9 & 1,450 & 5.1 & $90 \%$ & 2.6 & 1,305 & 4.57 \\
\hline Gladstone & \begin{tabular}{|l|} 
Australia \\
\end{tabular} & 7.8 & 2 & 19.0 & 2,436 & 8.5 & $53 \%$ & 10.1 & 1,291 & 4.52 \\
\hline Pacific LNG & Australia & 9.0 & 2 & 26.0 & 2,889 & 10.1 & $45 \%$ & 11.7 & 1,300 & 4.55 \\
\hline Tangguh Expansion & Indonesia & 3.8 & 1 & 8.0 & 2,105 & 7.4 & $50 \%$ & 4.0 & 1,053 & 3.68 \\
\hline Petronas PFLNG1 & Malaysia & 1.2 & 1 & 1.5 & 1,290 & 4.5 & $75 \%$ & 1.2 & 968 & 3.39 \\
\hline Elba Island & USA & 2.5 & 1 & 2.3 & 924 & 3.2 & $90 \%$ & 2.1 & 832 & 2.91 \\
\hline Petronas PFLNG2 & Malaysia & 1.5 & 1 & 1.7 & 1,100 & 3.9 & $75 \%$ & 1.2 & 825 & 2.89 \\
\hline Freeport & USA & 15.0 & 3 & 13.3 & 887 & 3.1 & $90 \%$ & 12.0 & 799 & 2.80 \\
\hline Corpus Christi T1-2 & USA & 9.0 & 2 & 10.4 & 1,160 & 4.1 & $90 \%$ & 9.4 & 1,044 & 3.66 \\
\hline Corpus Christi T3 & USA & 4.5 & 1 & 3.0 & 667 & 2.3 & $100 \%$ & 3.0 & 667 & 2.33 \\
\hline Cameron LNG & USA & 13.5 & 3 & 11.0 & 815 & 2.9 & $90 \%$ & 9.9 & 733 & 2.57 \\
\hline Cove Point & USA & 5.3 & 1 & 4.2 & 789 & 2.8 & $90 \%$ & 3.8 & 710 & 2.48 \\
\hline Bintulu Train 9 & Indonesia & 3.6 & 1 & 2.5 & 694 & 2.4 & $90 \%$ & 2.3 & 625 & 2.19 \\
\hline Caribbean FLNG & TBA & 0.5 & 1 & 0.4 & 800 & 2.8 & $75 \%$ & 0.3 & 600 & 2.10 \\
\hline Golar FLNG & Cameroon & 2.4 & 1 & 1.9 & 800 & 2.8 & $75 \%$ & 1.4 & 600 & 2.10 \\
\hline Sabine Pass Trains 1-4 & USA & 18.0 & 4 & 11.0 & 611 & 2.1 & $90 \%$ & 9.9 & 550 & 1.93 \\
\hline Sabine Pass Train 5 & USA & 4.5 & 1 & 3.8 & 844 & 3.0 & $100 \%$ & 3.8 & 844 & 2.96 \\
\hline
\end{tabular}



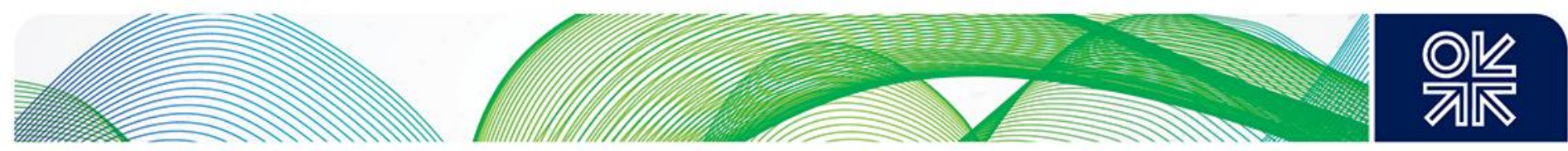

\section{References}

Project

Gorgon

Prelude FLNG

Wheatstone

Ichthys

Queensland Curtis

PNG LNG

Yamal LNG

Angola LNG

Donggi-Senoro

Gladstone

Australia Pacific LNG

Tangguh Expansion

Petronas PFLNG1

Elba Island

Petronas PFLNG2

Freeport

Corpus Christi T1-2

Corpus Christi T3

Cameron LNG

Cove Point

Bintulu Train 9

Caribbean FLNG

Golar FLNG

Sabine Pass Trains 1-4

Sabine Pass Train 5

\section{References}

https://australia.chevron.com/our-businesses/gorgon-project

https://www.oxfordenergy.org/wpcms/wp-content/uploads/2016/11/Floating-Liquefaction-FLNG-NG-107.pdf

https://www.offshore-technology.com/projects/wheatstone-project-carnarvon-basin/

http://www.inpex.com.au/our-projects/ichthys-Ing-project/ichthys-in-detail/project-overview/

https://www.hydrocarbons-technology.com/projects/queenslandcurtislng/

https://pnglng.com/About/Project-overview

http://yamallng.ru/en/project/about/

https://www.angolalng.com/en/about-angola-Ing/our-history-overview/

http://www.donggisenorolng.co.id/dslng-project/DSLNG-Project/eng

https://www.hydrocarbons-technology.com/projects/gladstone-project/

https://www.aplng.com.au/content/dam/aplng/compliance/eis/Volume_1/Vol_1_Chapter1_Introduction.pdf https://www.reuters.com/article/bp-indonesia-Ing-idAFJ9N16U014

https://www.oxfordenergy.org/wpcms/wp-content/uploads/2016/11/Floating-Liquefaction-FLNG-NG-107.pdf

https://www.kindermorgan.com/business/gas_pipelines/projects/elbaLNG

https://www.oxfordenergy.org/wpcms/wp-content/uploads/2016/11/Floating-Liquefaction-FLNG-NG-107.pdf

https://www.hydrocarbons-technology.com/projects/freeport-Ings-liquefaction-texas/

https://www.oxfordenergy.org/wpcms/wp-content/uploads/2016/11/Floating-Liquefaction-FLNG-NG-107.pdf

https://www.Ingworldnews.com/cheniere-amends-corpus-christi-Ing-deal-with-bechtel/

http://cameronlng.com/ImportExport.html

https://www.hydrocarbons-technology.com/projects/dominion-cove-point-liquefaction-project-chesapeake-bay/

http://www.pressreader.com/malaysia/the-star-malaysia-starbiz/20130313/281539403390233

https://www.oxfordenergy.org/wpcms/wp-content/uploads/2016/11/Floating-Liquefaction-FLNG-NG-107.pdf https://www.oxfordenergy.org/wpcms/wp-content/uploads/2016/11/Floating-Liquefaction-FLNG-NG-107.pdf https://www.2b1stconsulting.com/cheniere-10-billion-Ing-terminal-project-turns-to-export/

https://www.bechtel.com/newsroom/releases/2011/11/awarded-contract-sabine-pass-Ing-expansion/ 


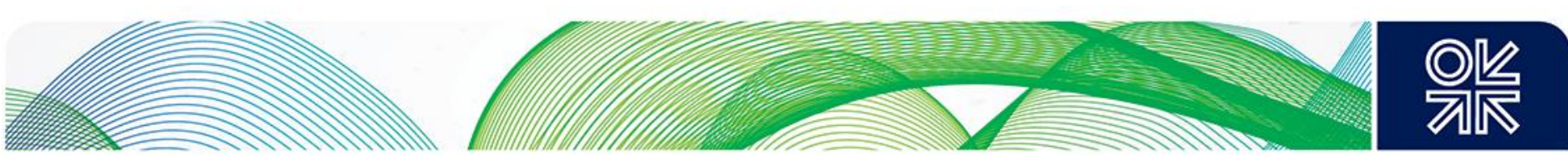

Appendix 2. Project Technical Details

\begin{tabular}{|c|c|c|c|c|c|c|c|c|}
\hline Project & Location & MTPA & Trains & Tanks & Jetties & Gas & Liquids & Comments \\
\hline Gorgon & Australia & 15.6 & 3 & 2 & 1 & Rich & Yes & 2 Jetty heads \\
\hline Prelude FLNG & Timor Sea & 3.6 & 1 & In FLNG & - & Rich & Yes & \\
\hline Wheatstone & Australia & 8.9 & 2 & 2 & 1 & Rich & Yes & \\
\hline Ichthys & Australia & 8.4 & 2 & 2 & 1 & Lean & Yes & Some condensate exported offshore \\
\hline Queenland Curtis & Australia & 8.5 & 2 & 2 & 1 & Lean & No & \\
\hline PNG & PNG & 6.9 & 2 & 2 & 2 & Lean & No & Liquids removed separately \\
\hline Yamal & Russia & 16.6 & 3 & 4 & 2 & Rich & Yes & \\
\hline Angola LNG & Angola & 5.2 & 1 & 2 & 2 & Rich & Yes & LNG jetty. Liquids jetty \\
\hline Donggi-Senoro & Indonesia & 2.0 & 1 & 1 & 1 & Rich & Yes & Sulawezi \\
\hline Gladstone & Australia & 7.8 & 2 & 2 & 1 & Lean & No & \\
\hline Pacific LNG & Australia & 9.0 & 2 & 2 & 1 & Lean & No & \\
\hline Tangguh Expansion & Indonesia & 3.8 & 1 & 0 & 0 & Rich & Yes & Additional jetty \\
\hline Petronas PFLNG1 & Malaysia & 1.2 & 1 & In FLNG & - & Lean & No & \\
\hline Elba Island & USA & 2.5 & 1 & & & Lean & No & Using existing tanks \& jetty \\
\hline Petronas PFLNG2 & Malaysia & 1.5 & 1 & In FLNG & - & Lean & No & \\
\hline Freeport & USA & 15.0 & 3 & 0 & 0 & Lean & No & Using existing tanks \& jetty \\
\hline Corpus Christi Phase 1 & USA & 9.0 & 2 & 2 & 1 & Lean & No & \\
\hline Corpus Christi Phase 2 & USA & 4.5 & 1 & 1 & 1 & Lean & No & Additional tank and jetty \\
\hline Cameron LNG & USA & 13.5 & 3 & 0 & 0 & Lean & No & Using existing tanks \& jetty \\
\hline Cove Point & USA & 5.3 & 1 & 1 & 0 & Lean & No & Using existing tanks \& jetty \\
\hline Bintulu Train 9 & Indonesia & 3.6 & 1 & 0 & 0 & Lean & No & Using existing tanks \& jetty \\
\hline Caribbean FLNG & TBA & 0.5 & 1 & In FLNG & - & Lean & No & Awaiting project \\
\hline Golar FLNG & Cameroon & 2.4 & 1 & In FLNG & - & Lean & No & Hilli Episeyo FLNG \\
\hline Sabine Pass Trains 1-4 & USA & 18.0 & 4 & 0 & 0 & Lean & No & Using existing tanks \& jetty \\
\hline Sabine Pass Train 5 & USA & 4.5 & 1 & 0 & 0 & Lean & No & Using existing tanks \& jetty \\
\hline
\end{tabular}

Source: By author based on analysis of published data 

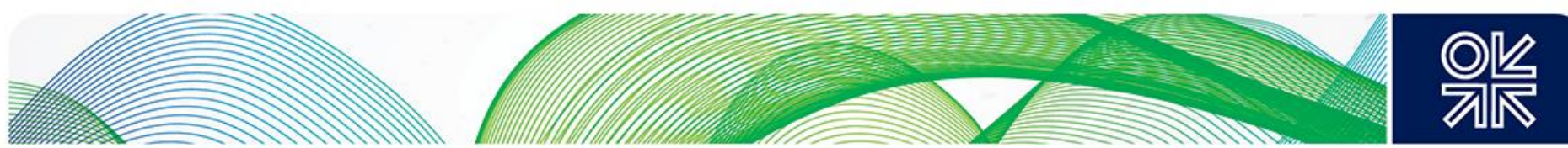

\section{Appendix 3. Capacity Factor}

The cost of a liquefaction plant is proportional to the capacity, in other words, the larger the plant the higher the cost. Plants are normally designed and constructed as nominal 4-5 mtpa units based around the use of industry standard gas turbines. Initially these were Frame 5 or Frame 7 industrial gas turbines but the industry has moved to using more efficient aero-derivative machines, such as LM-2500 and LM-6000. The major exception to this was the Qatar which used Frame 9 industrial turbines raising the capacity to $7.8 \mathrm{mtpa}$. The other limitation was the size of the main cryogenic heat exchanger (MCHE) ${ }^{57}$ if the $\mathrm{C} 3 / \mathrm{MR}$ process was used, which limits the train capacity to about 5 mtpa. Upgrades by $\mathrm{APCl}$ of their manufacturing facilities now means that the $\mathrm{C} 3 / \mathrm{MR}$ process can produce more than $5 \mathrm{mtpa}$ and more than $8 \mathrm{mtpa}$ for the AP-X process ${ }^{58}$.

For the larger Qatar trains the AP-X $\AA^{59}$ process was used which added an additional heat exchanger to the MCHE using nitrogen as a refrigerant. Recent announcements indicate that this process is being considered 60 for the expansion of the Qatar facilities to raise the production from 77 to $100 \mathrm{mtpa}$ by 2022. Exxon is also considering the larger AP-X process rather than C3/MR for Mozambique to reduce costs.

The cost capacity factor normally applied in the process plant industry is the $7 / 10^{\text {ths }}$ power rule: a unit of twice the size would cost $(2 / 1)^{0.7}=1.6$ more, giving an economy of scale. However, as the LNG plant industry is generally using standard 'building blocks' of 4-5 mtpa trains this does not directly apply.

While these industry standard units are generally being used for world-scale plants, smaller plants have been constructed, for example $2 \mathrm{mtpa}$ at Donggi-Senoro and $0.75 \mathrm{mtpa}$ trains on the Golar LNG FLNG units. Shell has developed the MMLS small-scale plants but these are focused on serving local markets and are used mainly for trucking. The range of LNG plant sizes is presented in figure 12.

\footnotetext{
'Coiled and ready for higher capacity': http://www.airproducts.com/ /media/downloads/article/L/en-Ing-industry-article-april2017.pdf?industryltem=Industries\&sublndustryltem=Energy\&segment=LNG\&applicationChildltem=Ingapplications\&productLevel3=MCR-Cryogenic-Heat-Exchangers 58 'THE C3MR LIQUEFACTION CYCLE: VERSATILITY FOR A FAST GROWING, EVER CHANGING LNG INDUSTRY': http://www.ivt.ntnu.no/ept/fag/tep4215/innhold/LNG\%20Conferences/2007/fscommand/PS2 5 Pillarella s.pdf 59 'Air Products' New AP-X® LNG Technology Placed On-Stream at World's Largest LNG Process Train in Qatar' http://www.airproducts.co.uk/Company/news-center/2009/07/0701-air-products-new-ap-x-Ing-tech-placed-on-stream-at-worldslargest-Ing-process-train-in-qatar.aspx

00 'Qatar Petroleum selects Chiyoda for North field production expansion FEED': https://www.Ingworldnews.com/qatarpetroleum-selects-chiyoda-for-north-field-production-expansion-feed//
} 

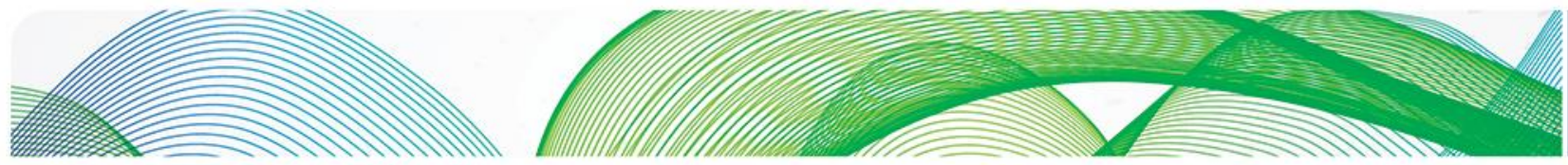

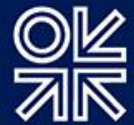

Figure 12: LNG Plant Capacity Range

\section{WHAT IS SMALL SCALE LNG?}

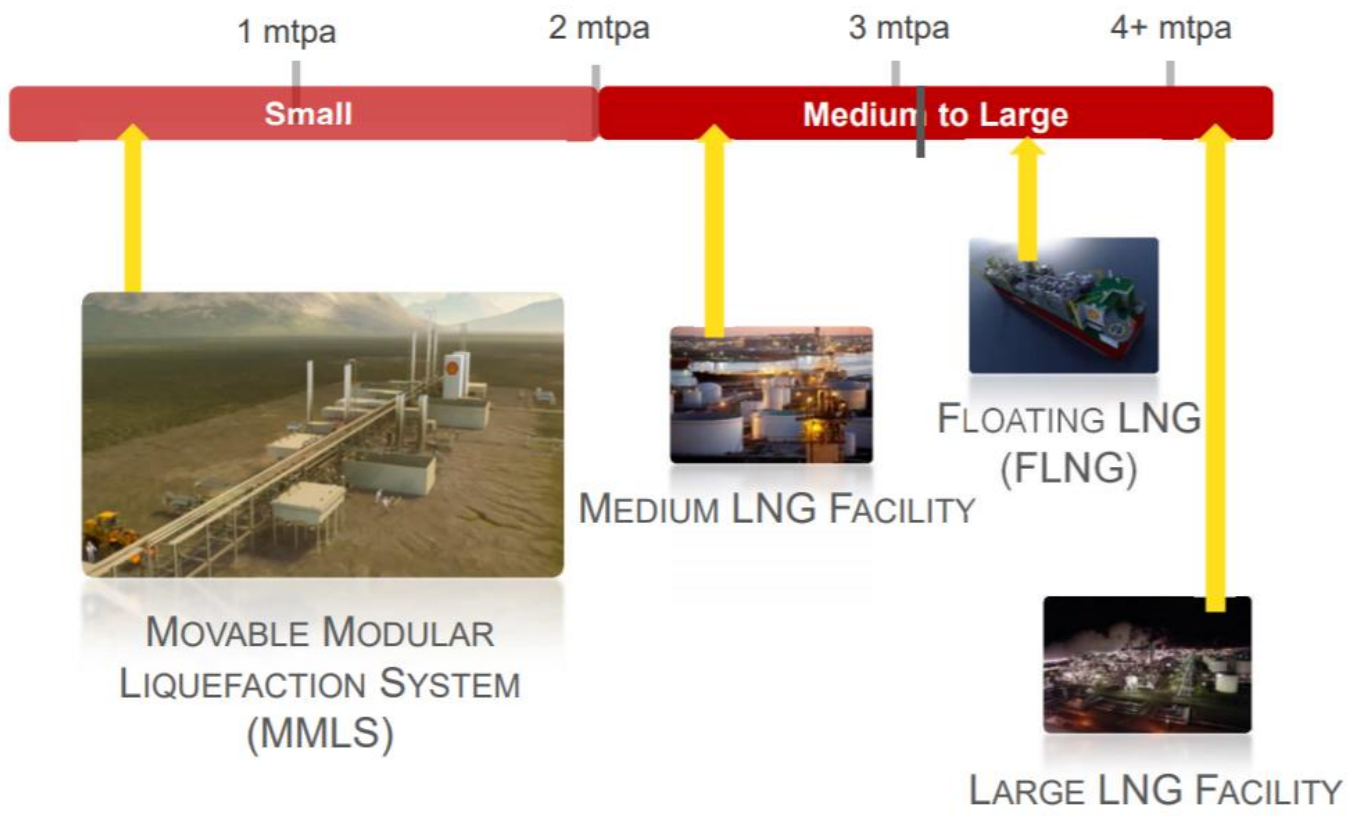

Copyright of ROYAL DUTCH SHELL

April $2013 \quad 6$

Source: Courtesy of Royal Dutch Shell 

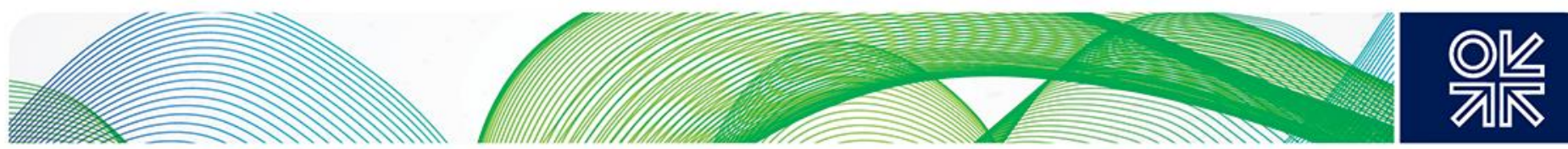

\section{Appendix 4. Complexity Factor}

The complexity factor adjusts for the scope of the processing facilities, in other words from a simple base plant for the liquefaction of lean gas through the inclusion of LPG and condensate recovery to the sulphur recovery and possibly $\mathrm{CO}_{2}$ sequestration.

Based on the analysis of the projects studied for this paper the average complexity factor for moving from lean gas to rich gas processing is 110 per cent, as shown in figure 13.

Figure 13: Complexity Factor (Lean Gas $=100 \%$ ) Based on Analysis of Projects Studied

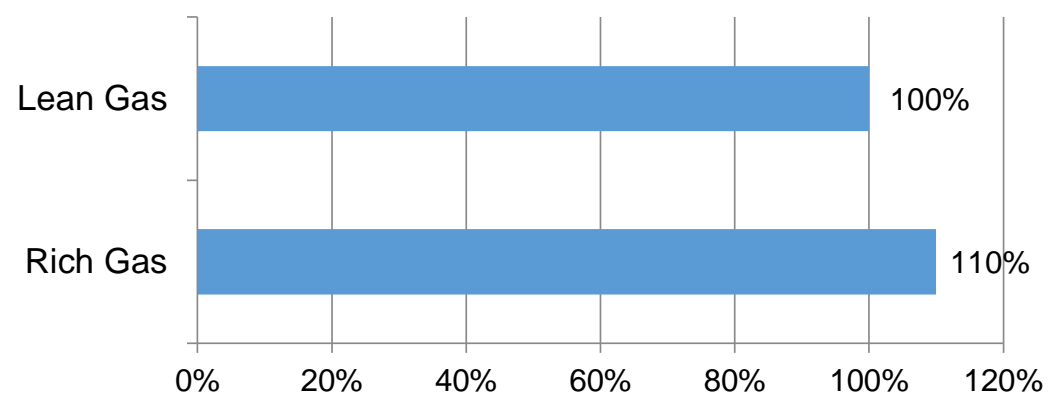

Source: Analysis by author

Another source of complexity factors is KBR's paper 'All LNG plants are not created equal' 61 . The factors quoted in their paper are based on the process plant only and not the overall cost including the tanks, jetty, utilities and infrastructure. Assuming the cost of the process plant represents 50 per cent of the overall project cost, the adjusted KBR factors are shown in figure 14. These factors are higher than the projects analysed for this paper, which probably reflects that the main condensate product was removed upstream.

Figure 14: Complexity Factors Based on KBR Paper but Adjusted \% Overall Project

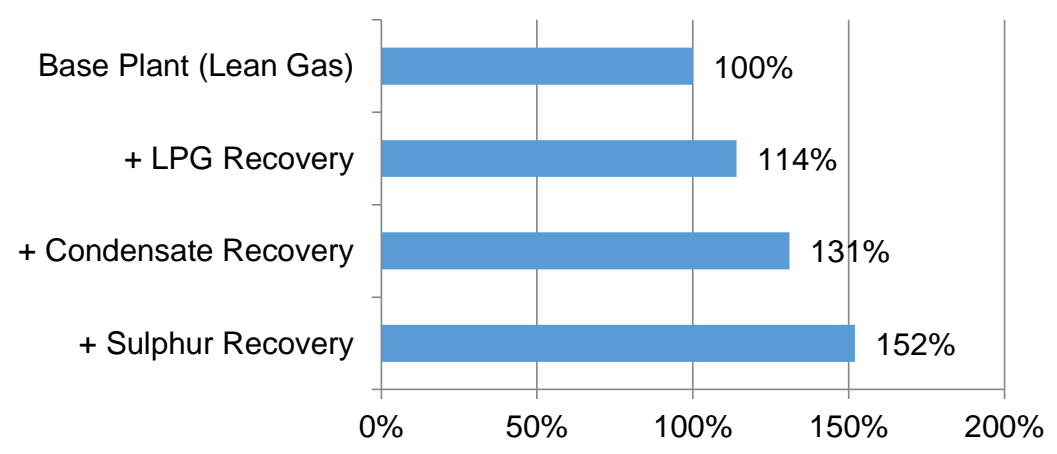

Source: KBR, Analysis by author 

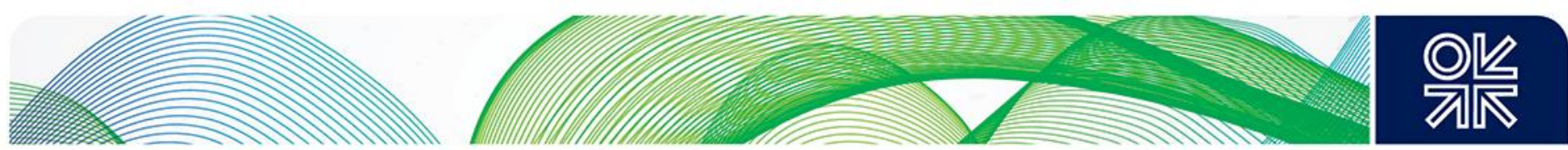

\section{Appendix 5. Location Factor}

This section determines the location factor by comparing projects at different locations but with the same capacity and complexity. Two main plant configurations were studied.

- Configuration A - Projects with two trains - two tanks - one jetty

- Configuration B - Projects with three trains - three tanks - one jetty

\section{Configuration A}

Table 8 compares the costs of the Corpus Christi, PNG, Queensland Curtis and Wheatstone projects. They all have the same scope: two liquefaction trains of nominal 4-4.5 mtpa capacity, two tanks and one jetty. The only difference for Wheatstone is the addition of condensate recovery and export which adds a slug catcher, fractionation plant, condensate tanks and ship loading. To enable a meaningful comparison the cost of Wheatstone has been reduced by 10 per cent for the removal the condensate facilities to enable comparison on a lean gas basis.

Table 8: Comparison of Two Trains, Two Tanks Projects

\begin{tabular}{|c|c|c|c|c|c|}
\hline Project & $\begin{array}{c}\text { Corpus } \\
\text { Christi } \\
\text { Phase 1 }\end{array}$ & PNG & $\begin{array}{c}\text { Queensland } \\
\text { Curtis }\end{array}$ & $\begin{array}{c}\text { Wheatstone } \\
\text { No } \\
\text { Condensate }\end{array}$ & $\begin{array}{c}\text { Wheatstone } \\
\text { Condensate }\end{array}$ \\
\hline Location & Texas & PNG & Queensland & NW Australia & NW Australia \\
\hline Capacity mtpa & $2 \times 4.5$ & $2 \times 4$ & $2 \times 4.25$ & $2 \times 4.25$ & $2 \times 4.25$ \\
\hline Tanks $\mathbf{m}^{\mathbf{3}}$ & $2 \times 160,000$ & $2 \times 160,000$ & $2 \times 140,000$ & $2 \times 180,000$ & $2 \times 180,000$ \\
\hline Gas Feed & $\begin{array}{c}\text { Lean } \\
\text { pipeline) }\end{array}$ & Lean & Lean (CSG) & Lean & Rich \\
\hline Condensate Export & No & No & No & Yes & Yes \\
\hline Jetties & 1 short & 1 medium & 1 short & 1 long & 1 long \\
\hline Liq CAPEX \$bn & 18 & 10.7 & 18 & 18.9 & 21 \\
\hline \$/tpa & 1,044 & 1,349 & 1,412 & 1,788 & 1,987 \\
\hline Ratio & $\mathbf{1 0 0} \%$ & $\mathbf{1 2 9} \%$ & $\mathbf{1 3 5 \%}$ & $\mathbf{1 7 1} \%$ & $\mathbf{1 9 0 \%}$ \\
\hline
\end{tabular}

Source: Analysis by author from various industry sources

The Australian dollar was very strong against the US dollar during 2014-2015, as shown in figure 15, which increased the cost of local materials and labour. Further the Australian projects were competing for local resources leading to exceptionally high labour rates. The costs would be lower now, with the weaker Australian dollar and less pressure on construction resources. 

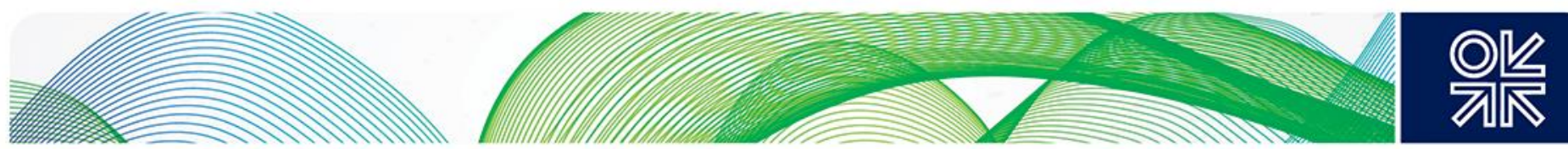

Figure 15: Australian Dollar vs US Dollar Exchange Rates 2014-18

Published on TradingView.com, February 07, 2018 12:16 GMT

FX_IDC:AUDUSD, 1W 0.78640 ₹-0.00409 (-0.52\%) 0:0.79187 H:0.79540 L:0.78320 C:0.78640

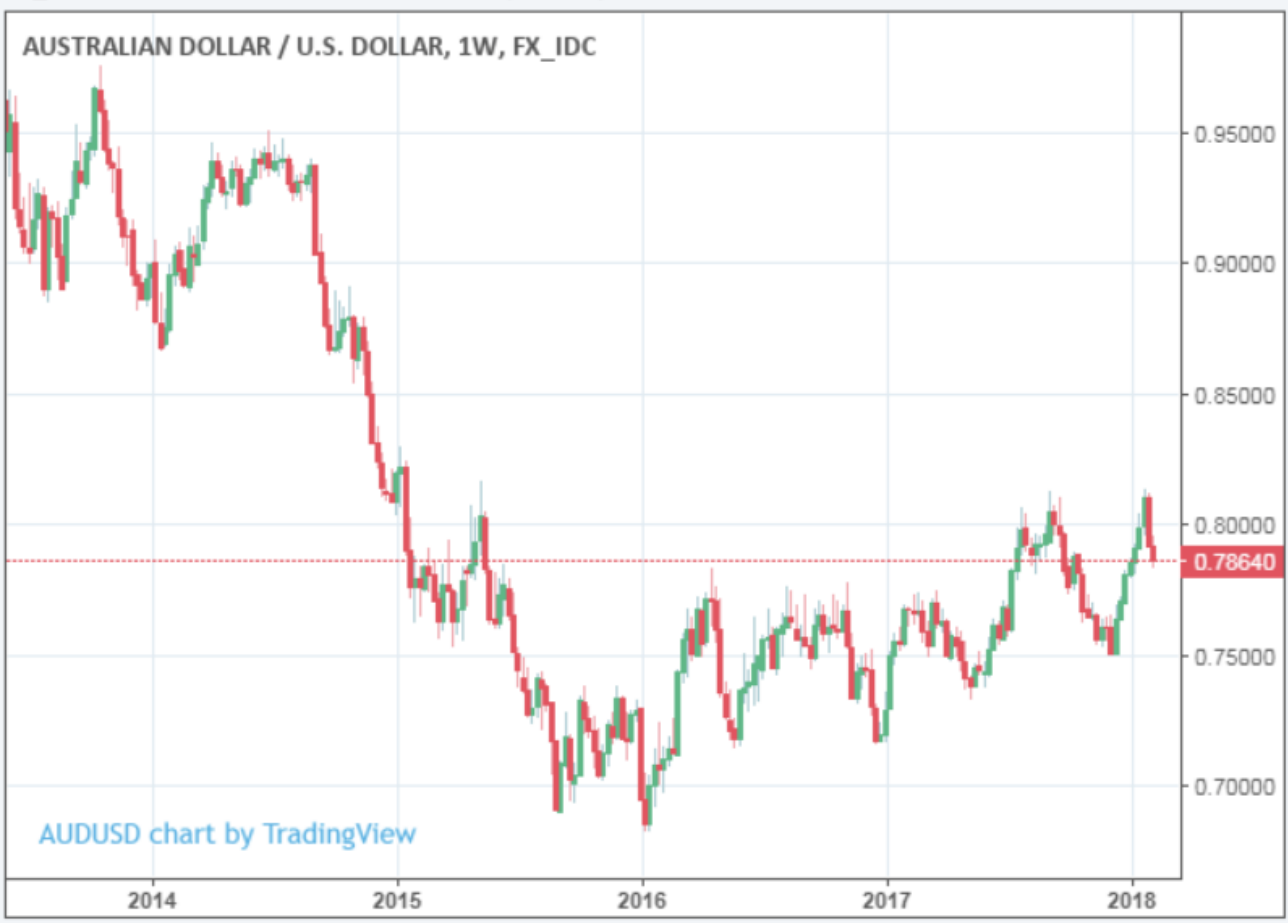

Source: Courtesy of Trading View

\section{Configuration B}

Table 9 compares the Yamal project with Corpus Christi (Phases 1 and 2). Both plants have three liquefaction trains. The Yamal plant has an additional fourth LNG tank.

To make the comparison on the same scope basis, the Yamal cost has been reduced for only three tanks and further reduced by 10 per cent to remove the condensate facilities enabling a like-with-like comparison with Corpus Christi. As shown, the cost of the adjusted Yamal project is 25 per cent higher than Corpus Christi, reflecting the higher construction costs in the harsh arctic environment. 

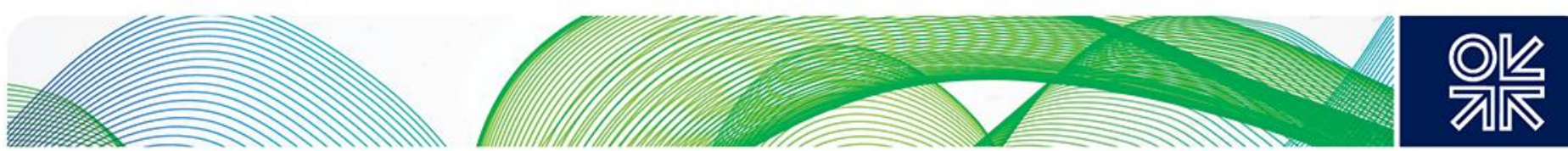

Table 9: Comparison of Three Trains, Three Tanks Projects

\begin{tabular}{|c|c|c|c|}
\hline Project & $\begin{array}{c}\text { Corpus Christi } \\
\text { Phase 1 + 2 }\end{array}$ & $\begin{array}{c}\text { Yamal } \\
\text { Adjusted for 3 } \\
\text { tanks, no } \\
\text { condensate }\end{array}$ & $\begin{array}{c}\text { Yamal } \\
\text { Base Case }\end{array}$ \\
\hline Location & Texas & Siberia & Siberia \\
\hline Capacity mtpa & $3 \times 4.5$ & $3 \times 5.5$ & $3 \times 5.5$ \\
\hline Tanks $\mathbf{m}^{\mathbf{3}}$ & $3 \times 160,000$ & $3 \times 160,000$ & $4 \times 160,000$ \\
\hline Gas Feed & Lean (pipeline) & Lean Gas & Rich Gas \\
\hline Condensate Export & No & No & Yes \\
\hline Jetties & 2 & 2 & 21.8 \\
\hline $\begin{array}{c}\text { Liquefaction CAPEX } \\
\text { \$billion }\end{array}$ & 12.4 & 19.12 & 1,313 \\
\hline \$/tpa & 919 & 1,152 & $\mathbf{1 4 3} \%$ \\
\hline Location Factor & $\mathbf{1 0 0} \%$ & $\mathbf{1 2 5} \%$ & \\
\hline
\end{tabular}

Source: Analysis by author from various industry sources

The location factors shown in tables 8 and 9 are summarized in figure 16.

Figure 16: Location Factor (USA $=100 \%$ ) Based on Analysis of Projects Studied

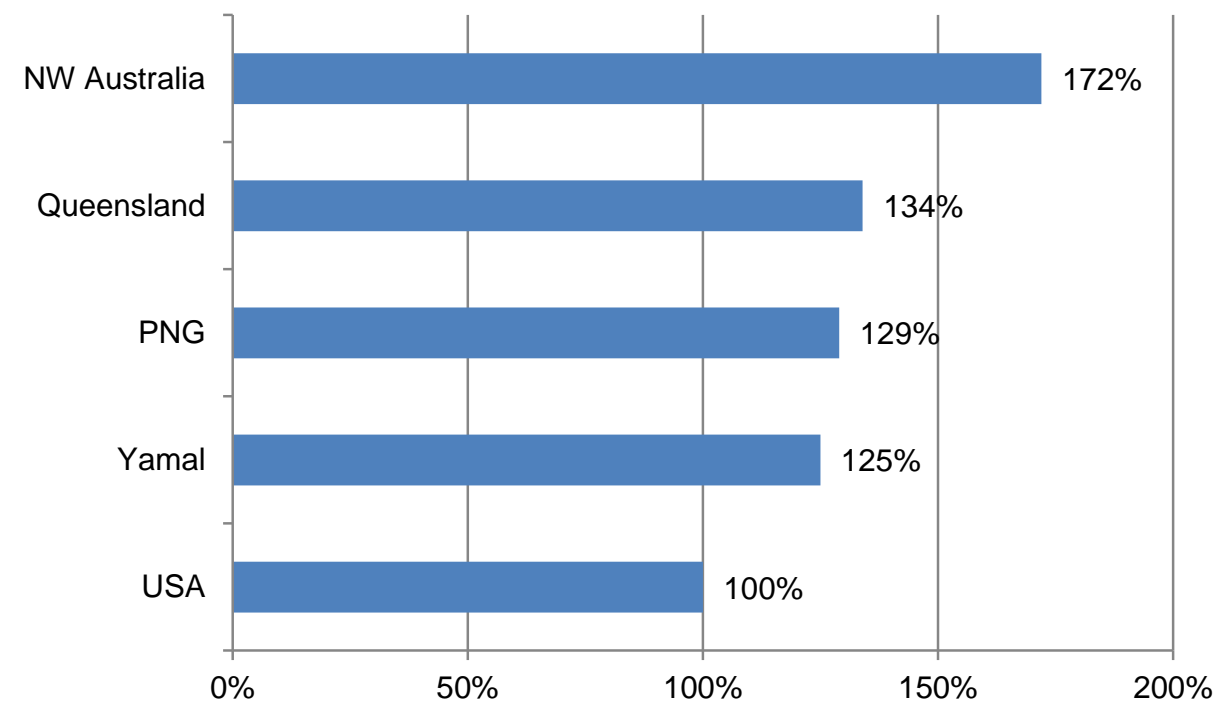

Source: Analysis by authors from various industry sources

In summary, the location factor is the largest cost driver for an LNG project and must be applied when assigning unit costs to a specific project. 

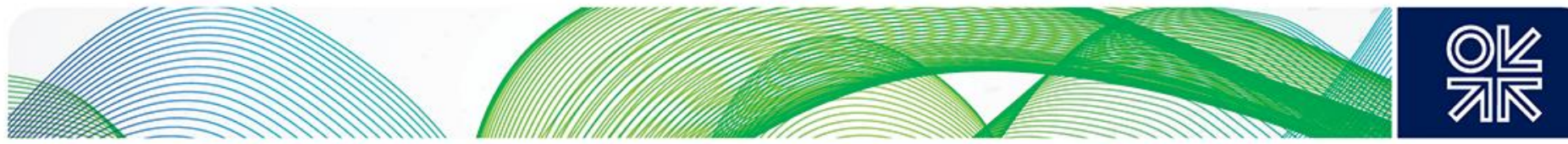

\section{Appendix 6. LNG Specifications}

\section{LNG CHARACTERISTICS}

The average composition is chosen as being representative among compositions reported by the different receiving terminals.

\begin{tabular}{|c|c|c|c|c|c|c|c|c|c|c|c|}
\hline Origin & $\begin{array}{c}\text { Nitrogen } \\
\text { N2 } \%\end{array}$ & $\begin{array}{c}\text { Methane } \\
\text { C1\% }\end{array}$ & $\begin{array}{l}\text { Ethane } \\
\text { C2 } \%\end{array}$ & $\begin{array}{l}\text { Propane } \\
\text { C3 \% }\end{array}$ & $\mathrm{C}_{4}+\%$ & TOTAL & $\begin{array}{l}\text { LNG Density }^{[x]} \\
\mathrm{kg} / \mathrm{m}^{3}\end{array}$ & $\begin{array}{c}\text { Gas Density }{ }^{(2)} \\
\mathrm{kg} / \mathrm{m}^{2}(\mathrm{n})\end{array}$ & $\begin{array}{c}\text { Expansion } \\
\text { ratio } m^{3}(n) / \\
m^{3} \text { liq }\end{array}$ & $\begin{array}{l}\text { Gas GCV (2) } \\
M J / m^{3}(n)\end{array}$ & $\begin{array}{c}\text { Wobbe Index(n) } \\
M \mathrm{M} / \mathrm{m}^{2}(\mathrm{n})\end{array}$ \\
\hline Australia - NWS & 0.04 & 87.33 & 8.33 & 3.33 & 0.97 & 100 & 467.35 & 0.83 & 562.46 & 45.32 & 56.53 \\
\hline Australia - Darwin & 0.10 & 87.64 & 9.97 & 1.96 & 0.33 & 100 & 461.05 & 0.81 & 567.73 & 44.39 & 56.01 \\
\hline Algeria - Skikda & 0.63 & 91.40 & 7.35 & 0.57 & 0.05 & 100 & 446.65 & 0.78 & 575.95 & 42.30 & 54.62 \\
\hline Algeria - Bethioua & 0.64 & 89.55 & 8.20 & 1.30 & 0.31 & 100 & 454.50 & 0.80 & 571.70 & 43.22 & 55.12 \\
\hline Algeria - Arzew & 0.71 & 88.93 & 8.42 & 1.59 & 0.37 & 100 & 457.10 & 0.80 & 570.37 & 43.48 & 55.23 \\
\hline Brunei & 0.04 & 90.12 & 5.34 & 3.02 & 1.48 & 100 & 461.63 & 0.82 & 564.48 & 44.68 & 56.18 \\
\hline Egypt - Idku & 0.02 & 95.31 & 3.58 & 0.74 & 0.34 & 100 & 437.38 & 0.76 & 578.47 & 41.76 & 54.61 \\
\hline Egypt - Damietta & 0.02 & 97.25 & 2.49 & 0.12 & 0.12 & 100 & 429.35 & 0.74 & 582.24 & 40.87 & 54.12 \\
\hline Equatorial Guinea & 0.00 & 93.41 & 6.52 & 0.07 & 0.00 & 100 & 439.64 & 0.76 & 578.85 & 41.95 & 54.73 \\
\hline Indonesia - Arun & 0.08 & 91.86 & 5.66 & 1.60 & 0.79 & 100 & 450.96 & 0.79 & 571.49 & 43.29 & 55.42 \\
\hline Indonesia - Badak & 0.01 & 90.14 & 5.46 & 2.98 & 1.40 & 100 & 461.07 & 0.82 & 564.89 & 44.63 & 56.17 \\
\hline Indonesia - Tangguh & 0.13 & 96.91 & 2.37 & 0.44 & 0.15 & 100 & 431.22 & 0.74 & 581.47 & 41.00 & 54.14 \\
\hline Libya & 0.59 & 82.57 & 12.62 & 3.56 & 0.65 & 100 & 478.72 & 0.86 & 558.08 & 46.24 & 56.77 \\
\hline Malaysia & 0.14 & 91.69 & 4.64 & 2.60 & 0.93 & 100 & 454.19 & 0.80 & 569.15 & 43.67 & 55.59 \\
\hline Nigeria & 0.03 & 91.70 & 5.52 & 2.17 & 0.58 & 100 & 451.66 & 0.79 & 571.14 & 43.41 & 55.50 \\
\hline Norway & 0.46 & 92.03 & 5.75 & 1.31 & 0.45 & 100 & 448.39 & 0.78 & 573.75 & 42.69 & 54.91 \\
\hline Oman & 0.20 & 90.68 & 5.75 & 2.12 & 1.24 & 100 & 457.27 & 0.81 & 567.76 & 43.99 & 55.73 \\
\hline Peru & 0.57 & 89.07 & 10.26 & 0.10 & 0.01 & 100 & 451.80 & 0.79 & 574.30 & 42.90 & 55.00 \\
\hline Qatar & 0.27 & 90.91 & 6.43 & 1.66 & 0.74 & 100 & 453.46 & 0.79 & 570.68 & 43.43 & 55.40 \\
\hline Russia - Sakhalin & 0.07 & 92.53 & 4.47 & 1.97 & 0.95 & 100 & 450.67 & 0.79 & 571.05 & 43.30 & 55.43 \\
\hline Trinidad & 0.01 & 96.78 & 2.78 & 0.37 & 0.06 & 100 & 431.03 & 0.74 & 581.77 & 41.05 & 54.23 \\
\hline USA - Alaska & 0.17 & 99.71 & 0.09 & 0.03 & 0.01 & 100 & 421.39 & 0.72 & 585.75 & 39.91 & 53.51 \\
\hline Yemen & 0.02 & 93.17 & 5.93 & 0.77 & 0.12 & 100 & 442.42 & 0.77 & 576.90 & 42.29 & 54.91 \\
\hline
\end{tabular}

(1) Calculated according to $1506578\left[\mathrm{~T}=-160^{\circ} \mathrm{C}\right]$. (2) Calculated according to $1506976\left[0^{\circ} \mathrm{C} / 0^{\circ} \mathrm{C} .1 .01325\right.$ bar $]$

Source: GIIGNL 2012 (The International Group of Liquefied Gas Importers) 

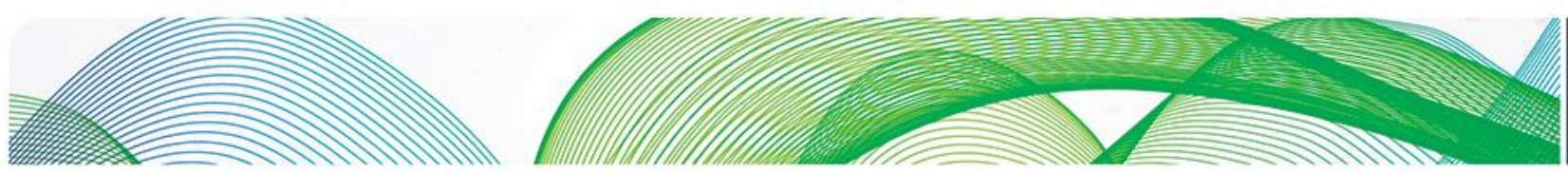

\section{O败}

\section{Bibliography}

2017 IGU World Gas Report, https://www.igu.org/sites/default/files/103419-

World IGU Report no\%20crops.pdf

OIES Report NG-83, 'LNG Plant Cost Escalation', https://www.oxfordenergy.org/wpcms/wpcontent/uploads/2014/02/NG-83.pdf

Tusiani, M. D. and Shearer, G. (2016). LNG: Fuel for a Changing World, A Nontechnical Guide, 2nd edition, Tulsa, OK, PenWell. Sample chapter at:

https://www.pennwellbooks.com/content/LNG Sample Ch1.pdf 